Portland State University

PDXScholar

1978

\title{
Günter Kunert: The artistic development of a writer of the German Democratic Republic
}

Jutta Southwell

Portland State University

Follow this and additional works at: https://pdxscholar.library.pdx.edu/open_access_etds

Part of the German Literature Commons

Let us know how access to this document benefits you.

\section{Recommended Citation}

Southwell, Jutta, "Günter Kunert: The artistic development of a writer of the German Democratic Republic" (1978). Dissertations and Theses. Paper 2857.

https://doi.org/10.15760/etd.2851

This Thesis is brought to you for free and open access. It has been accepted for inclusion in Dissertations and Theses by an authorized administrator of PDXScholar. Please contact us if we can make this document more accessible: pdxscholar@pdx.edu. 
AN ABSTRACT OF THE THESIS OF Jutta Southwell for the Master of Arts in German presented November 1, 1978.

Title: Günter Kunert: The Artistic Development of a Writer of the German Democratic Republic.

APPROVED BY MEMBERS OF THE THESIS COMMITTEE:

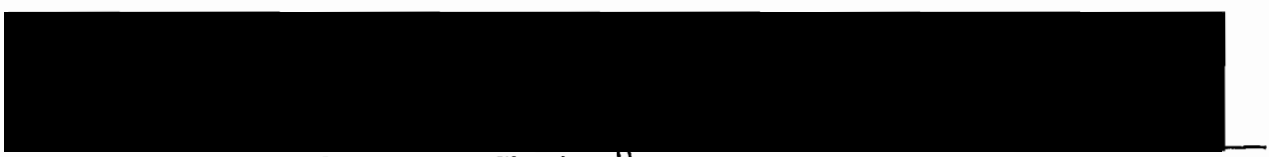

Franz Langhammer, Chairman

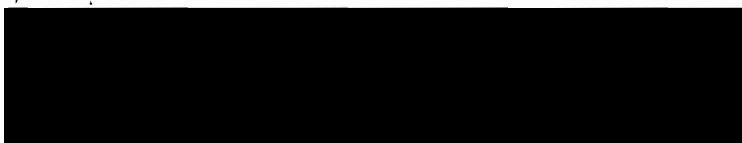

Louis J. Elteto

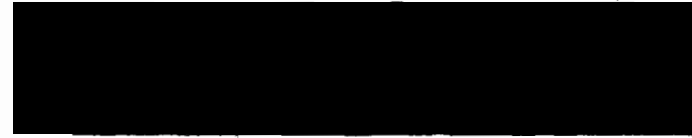

H. Frederick Peters

It is the purpose of this thesis to present the artistic development of the socialist writer Günter Kunert. He is considered to be one of the important representatives of the literature of the German Democratic Republic where he has spent most of his life. His artistic creativity stretches over three decades.

The different artistic and ideological periods of the development of this writer are presented in chronological order. An attempt is being made to explain why Kunert's work is of a politically provocative nature and why it shows such strong criticism towards the socialist 
country whose citizen he is.

The thesis follows the writer from his early socialist didactical works to the "Subjektivierung" of his writings in the present time. In conclusion, the thesis attempts to understand the deep-rooted reasoning of an author who in spite of his unmistakably critical position towards the GDR intends to remain there. 
GUNTER KUNERT: DER KUNSILERISCHE WEG EINES SCHRIFTSTELLERS DER DEUTSCHEN DEMOKRATISCHEN REPUBLIK

$$
\text { by }
$$

JUTTA SOUTHWELL

\begin{abstract}
A thesis submitted in partial fulfillment of the requirements for the degree of
\end{abstract}
MASTER OF ARTS
in
GERMAN

\author{
Portland State University \\ 1978
}


TO THE OFFICE OF GRADUATE STUDY AND RESEARCH:

The members of the Committee approve the thesis of Jutta Southwel1 presented November 1, 1978.

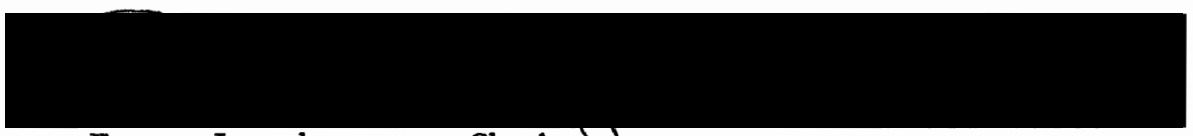

Franz Langhammer, Chairmah
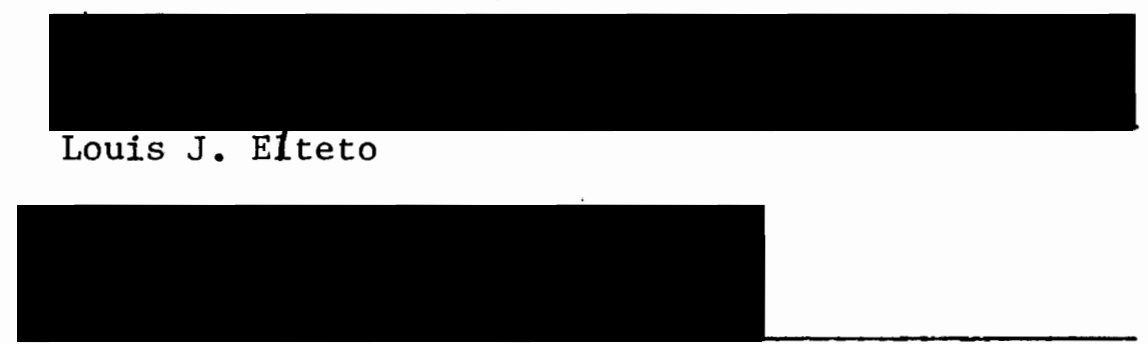

H. Frederick Peters

APPRÓVED :
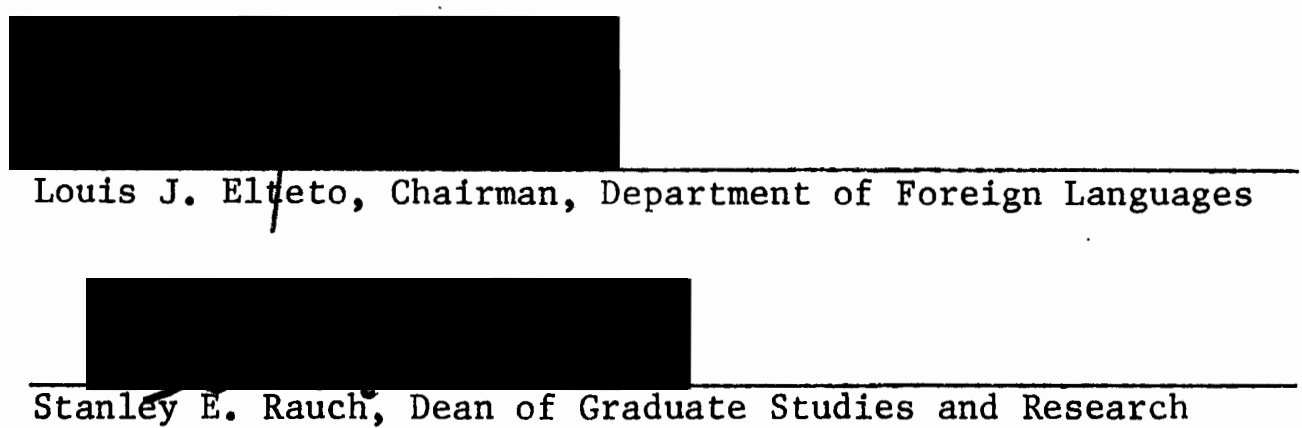
INHALT

KAPITEL

SEITE

EINLEITUNG

I DER FRUHE EINFLUß BRECHTS . . . . . . . . . 5

II DIE WENDUNG ZU KAFKA . . . . . . . . . . . 18

III NATURBILD ALS PARABEL . . . . . . . . . . . 29

IV STADTBESGHREIBUNGEN . . . . . . . . . . 40

V PARADOXIE ALS PRINZIP . . . . . . . . . 47

VI DAS LYRISCHE ICH . . . . . . . . . . . 53

VII DAS "BEWUßTSEIN" DES GEDICHTS . . . . . . . • . 58

ZUSAMMENFASSUNG . . . . . . . . . . . . . 67

FUBNOTEN •. . . . . . . . . . . . . . . . . . . . . .

LITERATURVERZEICHNIS . . . . . . . . . . . . . 78 


\section{EINLEITUNG}

Die Literatur der Deutschen Demokratischen Republik steht seit ihren Anfängen unter strenger, politischer Aufsicht. Das Zentralkomitee der Sozialistischen Einheitspartei (SED) bestimmt, was dem Staat von literarischem und politischem Nutzen sein könnte. Die Literatur soll als Werkzeug dienen, den neuen Staat aufzubauen und den Menschen im sozialistischen Sinn zu erziehen. Das ästhetische Dogma ist der "sozialistische Realismus", der in allen Kunstformen, auch in der Literatur, ausgedrückt werden soll. Er versucht, die Situation des sozialistischen Menschen in seiner Umgebung zu idealisieren. Diese Zweckliteratur hat die Aufgabe, den Leser auf die moralische und intellektuelle Uberlegenheit des Sozialismus hinzuweisen und ihm ein "sozialistisches Bewußtsein" zu geben. Dadurch wird der schreibende Künstler in einen Stoffkreis gezwungen, der sich vor allem auf die kämpfende Arbeiterklasse und die sozialistischen Ziele des Staates beschränkt. Die staatlich erwünschte Literatur erhält eine Lizenz, die für jedes Schriftstück notwendig ist, denn ohne diese Genehmigung kann und darf nichts gedruckt und verlegt werden. Diese Lizenz erfolgt nur nach Uberprïfung und Gutheißen der Rezensenten des Zentralkomitees. In westlich-demokratischen Ländern wird das Werk eines Schriftstellers oft von den Verlagen auf Grund seiner projizierten Verkaufbarkeit angenommen und vom Leser selbst auf seine Substanz und literarische Qualität geprüft. Diese Bewertung übermimmt in der DDR der Staat, der nicht nur nach literarischer Bedeutung sucht, sondern das Geschriebene auch auf Funktion und Unschädlichkeit kontrolliert. Das Zentralkomitee vertritt 
die Meinung, daß nur auf diese Weise ein antifaschistischer, demokratischer Wiederaufbau eines neuen Deutschlands möglich sei. Die Hauptthematik dieser gelenkten Literatur befaßt sich mit der Bewältigung der Vergangenheit, dem Kampf gegen den Imperialismus, der Erschaffung eines Arbeiter- und Bauernstaates und mit Sow jetpropaganda.

Nach den Ereignissen des 17. Juni 1953 tritt eine Anderung ein. Unter Leitung Johannes $R$. Bechers entsteht das Kulturministerium und eine kulturelle Erleichterung beginnt. Bis zu diesem Zeitpunkt hatten die Spielpläne der Theater fast ausschließlich aus Stücken bestanden, die sich mit sow jetischer Propaganda befaßten. In den Theatern erscheinen nun mehr und mehr Stücke, die nichts mit diesem Thema zu tun haben. Schriftsteller äußern zum ersten Mal öffentliche Kritik gegen die einengenden Richtlinien, die ihnen vom Staat auferlegt werden. Sie fordern mehr künstlerische Freiheit, um ihre literarischen Fähigkeiten voll ausdrücken zu können. Diese Zeitspanne der Erleichterung - auch "Tauwetter" genannt - kulminiert im Jahre 1956. Der Staat erkennt die potentielle Gefahr erneuter Unruhen und reagiert mit strengen Gegenmaßnahmen. Da er offene Kritik nicht toleriert, wird sie unterdrückt und von Neuem legt die Partei straffe, literarische Maßstäbe fest. Diese neue offizielle Literaturpolitik beginnt mit der Bitterfelder Konferenz am 24. April 1959 und dauert bis 1961.1 Schriftsteller und andere Künstler werden beauftragt, aktiv den wirtschaftlichen und sozialen Aufbau zu unterstiitzen und die Masse wird ermuntert, die „Höhen der Kultur zu erstürmen".2 Das Resultat: Schriftsteller werden in Fabriken und landwirtschaftlichen Betrieben angestellt und Arbeiter werden aufgefordert, ihre Gedanken zu Papier zu bringen. "Greif zur Feder, Kumpel:"3 Unter diesem Motto steht, was nun produziert wird: Betriebsromane und Arbeiteranekdoten. 
Nach dem Bau der Mauer im Jahre 1961 erfährt die Literatur der DDR jedoch einen künstlerischen Aufschwung, der sich stark von der "Zuckergußliteratur" des sozialistischen Realismus unterscheidet. Obwohl weiterhin spezielle Themen verlangt werden, die das sozialistische Menschenbild und den sozialistischen Lebensstil behandeln, beginnen einige Schriftsteller, unabhängig von der diktierten Richtlinie zu schreiben. Sie ziehen die Aufmerksamkeit des literarischen Westens auf sich. Das Zentralkomitee exlaubt diese Unabhängigkeit nur begrenzt und unterstreicht seine Macht mit gelegentlichen Schreibverboten. In besonders kritischen Fällen wird der Schriftsteller öffentlich denunziert und als dekadent und sozialismusmüde erklärt.

Bis zum Zeitpunkt der "Mauer" kann die Entwicklung der DDR Kulturpolitik in fünf Stufen eingeteilt werden: Die Jahre von 1945 bis 1949 umfassen den "antifaschistischen, demokratischen Wiederaufbau"; von 1949 bis 1953 schult man sich an den sowjetischen Richtlinien für sozialistischen Realismus, um den "Ubergang zu einer sozialistischen Kulturrevolution" zu erleichtern; die Jahre 1953 bis 1956 zeigen kulturelle Erleichterungen, die 1956 mit dem "Tauwetter" enden; darauf folgen zwei Jahre von 1957 bis 1959 mit verstärkten parteilichen Richtlinien; die Jahre 1959 bis 1961 zeigen den Bitterfelder Plan in die Praxis umgesetzt; und als sechste Stufe, 1961 bis zur Gegenwart, kann die Periode angeführt werden, die ein ständiges Auf und $\mathrm{Ab}$ von Lockerungen und strafferen Richtlinien ist. Viele DDR Schriftsteller suchen ihre Freiheit in der Lyrik, die ihnen ein freieres Ausdrucksgebiet als die Prosa bietet. In der persönlichen Sphäre der Lyrik, in ihren vielschichtigen Bereichen, gibt es Möglichkeiten für einen Schriftsteller, individuell zu bleiben. Wenn in der 
kritischen Prosa der DDR eine besondere Schlüsselsprache notwendig ist, so kann die Lyrik leichter ihre eigenen kryptischen Verschlüsselungen benutzen.

Günter Kunert, dessen Prosa und Lyrik bis zu den Anfängen der DDR Literatur zurückreicht, muß als einer ihrer wichtigsten Repräsentanten anerkannt werden. Was Kunert jedoch besonders bemerkenswert und provokativ erscheinen läßt, ist die auffallend politische Tendenz in seinen Schriften, die sich ungewöhnlich oft in Kritik am DDR Staat manifestiert. Die Frage, wie es möglich sei, diese Kritik in einem diktatorischen Staat zu veröffentlichen, veranlaßt zu näherer Betrachtung von Kunerts Stil. Wenn man davon ausgeht, daß die Lyrik eine natürliche Form der Verschlüsselung sein kann, so ist das eine Erklärung dafür, daß Kunerts Kritik hauptsächlich in seinen Gedichten zu finden ist. Jedoch formuliert er Kritik in den letzten Jahren zunehmend auch in seiner Prosa.

Die wichtigsten literarischen Einflüsse auf Kunerts Werk und die stilistischen Mittel, die er verwendet, sollen hier ebenfalls angeführt werden.

Es wird also in dieser Arbeit versucht, Kunerts künstlerische und ideologische Entwicklung zu verfolgen. Die verschiedenen Phasen dieser Entwicklung - von früher sozialistischer Didaktik bis zur Subjektivierung seiner Schriften - sollen hier nachvollzogen werden.

Schließlich wird versucht, zu verstehen, welche Gründe diesen Dichter bewegen mögen, trotz seiner unmißverständlich kritischen Haltung in der DDR zu bleiben. 
DER FRUHE EINFLUB BRECHTS

Kunert bekennt, sich an den verschiedensten Stilarten geschult zu haben und führt Namen wie Brecht, Becher, Rilke, Kafka, Catull und Heine an.I In Technik und Thematik macht er vielfach Anleihe bei diesen Vorbildern. Die folgenden zwei Kapitel beschränken sich jedoch auf Brecht und Kafka.

Kunerts Affinität zu Brecht zeigt sich hauptsächlich in seinen frühen Gedichten. In den füfziger Jahren besteht seine Lyrik meist aus Lehroder Warngedichten, die sich mit den Schrecken der Vergangenheit befassen und die als Werkzeug dienen sollen, einen neuen Menschen zu erschaffen. Der Gedichtband Erinnerungen an einen Planeten, der 1963 in der Bundesrepublik erschien, enthält eine Reihe von frïhen Gedichten, die dieses Genre aufzeigen. Das kurze Gedicht, „Uber Einige Davongekommene", bereits 1950 erschienen, mag als Beispiel für Kunerts Warngedichte dienen:

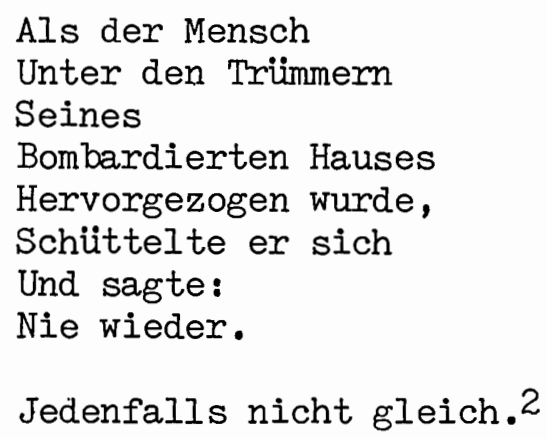

Oder ein anderes aus der gleichen Sammlung stammendes Gedicht, das 1955 erschien: 
DIE WOLKEN SIND WEIß, WEIß IST

Die Milch im Krug, weiß wie die

Windprallen Hemden auf der Leine, weiß

Wie Verbandstoff vor der Schlacht. (S.2I)

In diesen Gedichten sind Lehre und Warmung offensichtlich. Die Didaktik dieser Lyrik ist charakteristisch für die frïhen Gedichte Kunerts. Den Brechtschen Ansatz in Richtung auf das Lehrgedicht entwickelt Kunert jedoch zu seinem eigenen und entfermt sich damit von der üblichen Definition. Er hält alle realistischen Gedichte für Lehrgedichte, aber nicht mehr im Brechtschen Sinn. Für Kunert bedeuten seine Lehrgedichte, die er "schwarze" Lehrgedichte nennt, eine andere Möglichkeit, aus einer "Lehre" eine Gegenlehre zu ziehen, indem er das Negative als Ziel zeigt und sozusagen mit schlechtem Beispiel vorangeht. Er definiert diese Gattung selbst:

Ich rede von der realistischen Lyrik. Und damit meine ich nicht diese, in der es so zugeht, wie auf einem Foto, oder wie in der sichtbaren Realität; realistische Lyrik ist für mich eine, deren Spannungsmoment oder Grundmotiv oder Absicht oder Erkenntnis in der Wirklichkeit, in unserer gegenwärtigen Wirklichkeit liegt. Der Realismus liegt im Gleichnis, in der Gesamtmetapher, im Gestus - nicht unbedingt in dem, was da auf dem Papier steht.3

Das schwarze Lehrgedicht charakterisiert sich weiter - wie Laschen bemerkt - durch ein internes, verdecktes Sprechen, das in der Verdeckung erst als Gleichnis und als dieses übertragbar auf bestimmte Realitäten erscheint. 4 Im schwarzen Lehrgedicht greift Kunert auf die parabolische Form zurück, die inm das Aussprechen der Wahrheit - wie er sie sieht ermöglicht. Sprachlich bis zum Epigramm verkiurzt ist der folgende Text, der auf bestimmte Realitäten in Kunerts politischer Umgebung hinzuweisen scheint: 


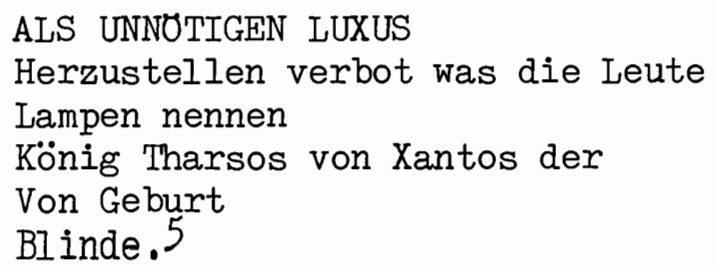

Wie Kunert sagt, liegt für ihn das Grundmotiv der Lyrik in seiner gegenwärtigen Wirklichkeit. Zwar kleidet er hier diese Wirklichkeit in eine gleichnishafte Form und verleiht ihr einen historischen Charakter, wodurch aber das Gegenwartsmoment nicht verdeckt wird. Obwohl die zweite Zeile im Imperfekt steht, wird sie von der Präsensform in der dritten abgelöst. Entbehrungen verschiedenster Art, sei es Luxus oder "lux" - im Sinne von Licht oder Erleuchtung - bedeuten gegenwärtige Wirklichkeit. Ein weiteres Beispiel ist das 1963 entstandene Gedicht, "Die Drei Heiligen Affen", das Kunerts Definition der realistischen Lyrik entspricht. "Der Realismus liegt im Gleichnis, in der Gesamtmetapher, im Gestus - nicht unbedingt in dem, was da auf dem Papier steht."

Weltbekannt und nachgeformt aus

Vielerlei Material ward die Gruppe

Dreier kleiner Affen

Vom großen Hindutempel in Benares.

Das eine der Tiere

Verschließt in ängstlicher Gebärde

Mit den Händchen den Mund, das zweite die Augen,

Und das dritte hält sich die Ohren zu.

Die blutigen Kriege der Khane und die Verzweifelten Gefechte der Bergvölker

Gegen die immer weiter

Vorrückenden Fremden überdauerten

Die grauen Figürchen;

Wie auch

Die wild übers Land strudelnden Wasser

Des Hindukusch und des Indus, uiberdauerten

Dschungelbrände und aufstrotzende

Baumgiganten, Rodung und Eisenbahndamm. 
Wer nicht alles hört, was geschieht, Nicht alles sieht, was vor ihm getan wird, Und nicht alles sagt, was er weiß: er nur Wird sehr alt.

Freilich eines gehört unabdingbar

$\mathrm{Zu}$ diesem Verhalten: daß man

Bis ins Herz aus Stein ist. 6

Dieses Gedicht zeigt inhaltlich Parallelen zu "Wie ich ein Fisch wurde".? Zwar handelt es sich hier nicht um eine einzige Katastrophe, sondern um eine scheinbar endlose Reihe von Ereignissen. Das zugrundeliegende Thema ist jedoch identisch: Wie verhält sich der Mensch angesichts einer Katastrophe, die ihn in historischem oder politischem Sinn betrifft? In "Wie ich ein Fisch wurde" beantwortet Kunert die Frage durch Veränderung bis zur totalen Anpassung: "Leben heißt: Sich ohne Ende wandeln./Wer am Alten hängt, der wird nicht alt." Uberleben ist das Wichtigste. In "Die Drei Heiligen Affen" zeigt Kunert eine andere menschliche Alternative, Konfrontationen auszuweichen. Er gebraucht dazu die Gestik der drei Affen als Metapher. In der vorletzten Strophe ist eine klare Parallele zum Motif des Uberlebens zu finden: (wer)„...nicht alles sagt, was er weiß: er nur/Wird sehr alt." In beiden Gedichten weist er also darauf hin, daß das Verhalten der Menschen - sich entweder anzupassen oder sich zu distanzieren - einen hohen Preis fordert: Das "Menschsein" ist vergessen und man ist "bis ins Herz aus Stein".

Die Erkenntnis der Wirklichkeit, der Realismus der Lyrik, sind grundlegende Elemente in Kunerts Dichtung. Es scheint aber, als ob ein notwendiges drittes Element unausgesprochen bleibt: Die Wahrheit. Aber um die Wahrheit in einem diktatorischen Staat zu schreiben - sei er faschistisch oder kommunistisch - sind verschiedene Schwierigkeiten zu bewältigen. Brecht formulierte fün dieser Schwierigkeiten, die heute, wie da- 
mals, zutreffen. Kunert würde es mit Sicherheit nicht verneinen, wenn man ihn fragte, ob diese fünf Schwierigkeiten auch auf ihn zutreffen.

Wer heute die Liige und Unwissenheit bekämpfen und die Wahrheit schreiben will, hat zumindest fün Schwierigkeiten zu überwinden. Er muß den Mut haben, die Wahrheit zu schreiben, obwohl sie allenthalben unteŕdriickt. wird; die Klugheit, sie zu erkennen, obwohl sie allenthalben verhuillt wird; die Kunst, sie handhabbar zu machen als eine Waffe; das Urteil, jene auszuwählen, in deren Händen sie wirksam wird; die List, sie unter diesen zu verbreiten. Diese Schwierigkeiten sind groß für die unter dem Faschismus Schreibenden, sie bestehen aber auch für die, welche verjagt wurden oder geflohen sind, ja sogar fïr solche, die in den Ländern der bürgerlichen Freiheit schreiben. ${ }^{8}$

Kunert versucht, diese Schwierigkeiten zu bewältigen, indem er sich gerade des schwarzen Lehrgedichts bedient. Er bringt das Wesen und die Funktion des Gedichtes auf eine Kurzformel, die er "Katalysator" nennt.9 Wenn bei Kunert der Katalysator oft zur Kritik wird, dann stimmt er auch in diesem Punkt mit Brecht überein.

Es ist völlig verkehrt, Kritik als etwas Totes, Unproduktives, sozusagen Langbärtiges $\mathrm{zu}$ betrachten. Diese Auffassung von Kritik wiinscht Herr Hitler zu verbreiten. In Wirklichkeit ist die kritische Haltung die einzig produktive, menschenwiirdige. Sie bedeutet Mitarbeit, Weitergehen, Leben. Wahrer. Kunstgenuß: ohne kritische Haltung ist unmöglich.10

Kunert zieht sich gelegentlich den Unwillen der Partei zu, so da $\beta$ er - ob seiner Kritik - als unproduktiv und unfortschrittlich bezeichnet wird. Fir inn bedeutet Kritik am politischen System jedoch Mitarbeit, Weitergehen, Leben, im wahrsten Sinne der Brechtschen Prägung.

Brecht schrieb in seinem Essay "Uber die Lyrik und den Staat": "Der Staat schädigt die fürstaatliche Literatur, wenn er die gegenstaatliche unterdrückt, er entmündigt, entzahnt, entsachlicht sie."ll Die Brechtsche Position des "Gebrauchswerts" von Dichtungen trifft auch auf 
Kunerts Schreibweise zu: „Das Dichten muß als menschliche Tätigkeit angesehen werden, als gesellschaftliche Praxis mit aller Widerspriichlichkeit, Veränderlichkeit, als geschichtsbedingt und Geschichte machend."l2 Kunert adressiert und appelliert wie Brecht. Die Themenanleihe, die er bei Brecht macht, schließt Sympathie mit den ungezählten Ungenannten ein, die sich nicht mißbrauchen lassen. Die Propagierung der Notwendigkeit des Lernens und der Wandlung (nicht: der Anpassung) wären andere anzuführende Beispiele für die Themenanleihe bei Brecht. Besonders in den frühen fünfziger Jahren sieht Kunert sich verpflichtet, Gedächtnisstützen anzubringen und Wegweiser beim Aufbau einer neuen Welt zu sein. 1955 schreibt er: "Die Gedichte sind allenfalls Wegweiser, welche die Gedanken des Lesers in eine Richtung lenken: in die der Wahrheit ... die Welt ist veränderungswert ... Das heißt: zu wertvoll, sie unverändert zu lassen."13 Das in der Sammlung Warnung vor Spiegeln enthaltene Gedicht, "Vorschlag", illustriert diese Gedanken:

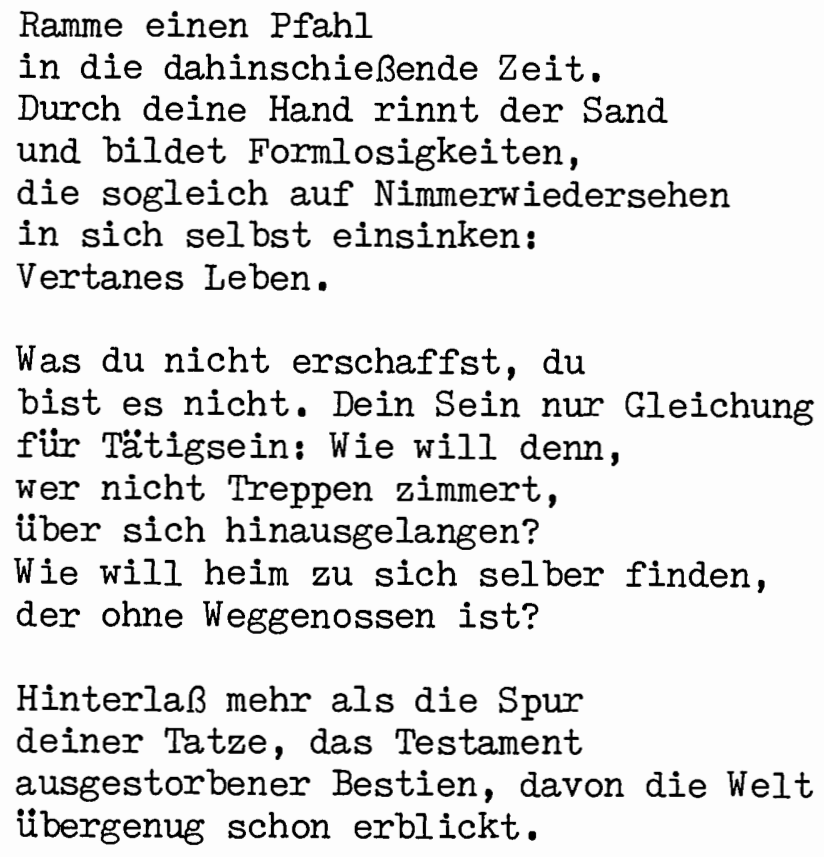


Ramme einen Pfahl ein. Ramme

einen einzigen, einen neuen Gedanken

als geheimes Denkmal

deiner einmaligen Gegenwart

in den Deich

gegen die ewige Flut. 14

Ein weiteres "Wegweisendes" Gedicht erscheint in diesen Zeilen:

\author{
LEISTEN \\ Von zwei Schustern einer \\ machte bequemere Schuhe \\ indes der andere beim alten Leisten \\ verharrte: Nicht Bequemlichkeit \\ des Fußwerks sei des Handwerks \\ Ziel \\ sondern: unnachgiebiges \\ Auftreten.15
}

Beide Gedjchte appellieren an das Verantwortungsgefuhl eines Jeden, der am Aufbau der "neuen Welt" beteiligt ist. Kunert ist davon iberzeugt, daß diese "neue Welt" nur von einem "neuen Menschen" erschaffen werden kann. Diesem Typus - dem er sich verwandt fühlt - setzt er Wegweiser, die darauf hindeuten, wie das Ziel erreicht werden kann. Im Gegensatz zu Brecht zeigt sich in Kunerts adressierenden Gedichten eine Ungeduld, die das Neue zu spontan fordert. In einem seiner frihesten Gedichte, "Fïr mehr als mich" (1950), bekennt er mit fast jünglingshaftem Pathos: "Ich bin ein Sucher/Eines Weges./Fir mehr/Als mich."l6 Dieses Gedicht ist Kunerts überzeugte, optimistische Erklärung an die Welt, daß es einen gemeinsamen Weg gibt, die neue Welt aufzubauen und daß er selbsṫ akitiv an diesem Aufbau beteiligt sein will. Der "neue Mensch", der sich der Vergangenheit bewußt ist und eine bessere Zukunft erhofft, soll das Instrument dazu sein. Kunerts Suche nach dem neuen Menschen scheint ihn jedoch entmutigt zu haben, denn dreizehn Jahre später schreibt er den „Bericht über ihn", ein Gedicht, das den Menschen aus einer durchaus anderen Sicht 
betrachtet: .

1

Wenig bekannt vor allen anderen

Ist ein Wesen besonderer Art: überzogen

Mit bläßlicher Haut, kaum behaart und gefüllt mit

Gedärm, Knochen und etwas Gehirn. Aufrecht sein

Gang, doch nicht sein Verhalten.

2

Kurz von Gedächtnis, denn bevor

An seinen Händen das Blut noch getrocknet,

Wei $\beta$ er schon nicht mehr, von wem her es stammt.

3

Seine Geschlechtsteile verbirgt er

Vor seinesgleichen wie einen kostbaren Schatz;

Aller Welt aber

Bietet er dar

Die geheimsten Zuckungen seiner Seele

Bis zum Uberdruß. Mindlich

Und schriftlich und bildlich.

4

In schwach erhellten Höhlen rechteckiger Form

Haust er und häuft darin an

Gestïhl und Geschränk und Gerät

Zur Wiedergabe von Lärm, bei welchem

Er Beine und Arme aufgeregt schwenkt.

5

Voller Schwächen, hat er eine Stärke, die

Ihn uniberwindbar macht: Er paßt sich an.

6

Wenn Regen fällt, spannt er seinen Schirm auf;

Fallen Bomben, stullpt er einen Hut aus Metall

Uber den Kopf und begibt sich in den Keller. Jeder

Situation ist er gewachsen.

7

Sehr kurz ist seine Zeit, doch dies nuitzt er,

Seinesgleichen die Zeit zu verkürzen. Er

Hat sich gewöhnt, daß Tag um Tag, Jahr um

Jahr

Ihm durch die Hand rinnt und nichts hinterläßt

Als Risse und Falten und Schwielen.

8

Vergangene Götter anzubeten

Ist ihm lange Gewohnheit, doch stellt er sich um

Auf gegenwärtige, wenn sie Macht haben, 
Diese so zu mißbrauchen und Ihn dazu.

9

An seinem Weg der erste Tote

Entsetzt ihn. Nicht mehr der Zehnte.

Den hundertsten übersieht er.

10

Er kennt alles Elend der Welt, aber

Er hat sich an alles gewöhnt, sofern

Es den Nachbarn betrifft.

11

Wahrlich, die Stärke, die ihn

Uberleben Iieß die Jahrtausende, sehet

Mit Verwunderung.

12

Er selber nennt sich: Mensch.

Selten ist er es. Es zu sein, danach strebt er

Manchmal.

Daß er es werde,

Treibt ihn an.17

Jeder Vers enthält Kritik und Anklage. Kunert zeigt ein Bild des Menschen mit brutaler Offenheit: Lächerlich in Gestalt, egozentrisch, spießbürgerlich, kaltblütig und ziellos. Ist das der Mensch, der mit seinesgleichen Sucher eines Weges sein soll? Kunert scheint zu der Uberzeugung gekommen zu sein, daß sich die Suche nach dem "neuen Menschen" nicht lohne, da es ihn ohnehin nicht gibt. Der Mensch bleibt das, was ihn über Jahrtausende überleben ließ. Kunert resigniert und doch ist eine vorsichtige Hoffnung in der letzten Strophe zu spüren. Der einzige Konjunktivsatz in dem Gedicht drückt diese Hoffnung aus: (Mensch) "... Daß er es werde, treibt ihn an."

Mit diesem Gedicht hat sich Kunert weit entfernt von den frühen Brechtschen Ansätzen. Der wegweisende, appellierende Ton hat einem zynischen, fast nihilistischen Platz gemacht, der in den sechziger und siebziger Jahren überwiegend in seinem Stil zu finden ist. 
Kunert macht weitere Anleihen bei Brecht, indem er Porträt-Gedichte und porträtierende Essays schreibt. Jedoch im Gegensatz zu Brechts Gedichten aus den zwanziger Jahren, die sich mit einer Abwertung großer Männer der Geschichte befassen, zeigt Kunert eine Aufwertung wirklicher Größe, die der Vermittlung von Tugenden und Vorbildern dient. Brechts Gedichte, "Von den großen Männern" und "Ich sage ja nichts gegen Alexander", behandlen historische Größe, die er als Scheingröße darstellt. "Von den großen Männern" sagt er beispielsweise in der letzten Strophe:

Die großen Männer tun, als ob sie weise wären Und reden sehr laut - wie die Tauben. Die großen Männer sollte man ehren Aber man sollte ihnen nicht glauben. 18

Die Leugnung historischer Größe liegt auch in "Ich sage ja nichts gegen Alexander" auf der Hand. Es beginnt mit der Zeile: "Timur, höre ich, nahm sich die Mühe, die Erde zu erobern."19 Die Sinnlosigkeit dieser Tat unterstreicht Brecht mit der dritten Zeile: „Mit etwas Schnaps vergißt man die Erde." Alexander wird Timur zugeordnet und Brecht stellt sie den Leuten gegenüber, die die gleiche Energie zum einfachen Uberleben aufbringen müssen, wie Timur und Alexander zum Erobern der Welt. Ihnen, den historisch Unbedeutsamen, mißt er wahre Größe bei.20

Kunert, hingegen, nimmt einen handkolorierten Druck, der den ungarischen Freiheitsdichter Alexander Petröfi in einer Schlacht zeigt, zum Anlaß, seine historische und literarische Größe zu preisen. In seiner „Notiz zu Petöfi" schreibt er:

Seit 1848 ist eine ganze Menge Zeit vergangen. Seit 1848 hat sich manches geändert, manches nicht. Das wïrden wir nicht erkennen können, besäßen wir keine unterschiedlichen Bezugssysteme, von denen eines Literatur heißt; in dieser Literatur den Meßwertgeber "Lyrik", und in der Lyrik wiederum als eine Skalenziffer 
den Petröfi. Veränderungen, Revolutionen, Konstanten, Regressionen werden kenntlich, spricht man sie mit dem Wort des Dichters an: "Ach, Poesie, wie hat man dich entwïrdigt, wie stieß man in den Staub dein edles Haupt, Dummköpfe taten das, die übereifrig strebten, erspart euch eure Predigt, schweigt, ihr Schwindler, keins eurer Worte hält der Wahrheit stand, die Poesie ist nicht an ihrem Platz, wo Eitelkeit, Geschwätzigkeit sich spreizt, wo sich das Unkraut der Gesellschaft sammelt. . . ."2l

Kunert bezieht Petöfi hier in seine Wirklichkeitsebene ein, indem er ihn als Maßstab hinstellt, um zu erkennen, was sich seit 1848 geändert hat und was gleich geblieben ist. Die Nebeneinanderstellung der Wörter „Veränderungen", "Revolutionen", "Konstanten" und "Regressionen" ist bemerkenswert. Möglicherweise sieht Kunert diese Gruppierung als logische Reihenfolge im Zyklus der Geschichte. Er scheint zu sagen, daß nach den Veränderungen, Revolutionen und Konstanten unaufhaltsam Regressionen eintreten, unter denen auch die Poesie zu leiden hat. Seine Affinität zu Petöfis Worten ist daher nicht verwunderlich, denn 130 Jahre später befindet Kunert sich in einer regressiven Periode, die sich durch die staatliche Zensur besonders auf Schriftsteller auswirkt. In seinem Essay schreibt Kunert weiter, daß Petöfis Zeilen auf Leute gemünzt seien,

- . die nicht auf einem handkolorierten Druck, sondern höchst real existieren und die nicht wissen, daß Petöfi mit seinem Säbel seit 1848 auf sie zeigt.

Uber diesen relativ kleinen Aspekt hinaus erweist sich Petöfis Dichtung in ihren Implikationen jeder anderen Weltdichtung verwandt: nämlich in Sachen Dialektik: durch den unauflöslichen Widerspruch von Scheitern und Triumphieren, Wirkung und Wirkungslosigkeit, Romantik und Realität, Pose und Haltung, unsterblicher Idee und erstorbener Ideologie: ein Beispiel für alle, die ihrer eigenen Humanisierung durch Beispiele bewußt sind: ein Beispiel für mich.22

In dem neunzeiligen Gedicht "Demokrit” spiegelt sich Kunerts Bewunderung eines anderen großen Mannes wider: 
Zwölf Jahre Meditation

über das Wesen der Luft.

Vorhanden - doch nicht greifbar;

leicht - doch großen Druckes fähig;

ihr Fehlen - unser Tod.

Auf der Suche nach einer

schluissigen Definition findet sich

unverhofft

die definierte Wahrheit.23

Andere Persönlichkeiten, die Kunert in Porträt-Gedichten beschreibt, sind zum Beispiel Lenin, Marx, Becher, Edgar Lee Masters, Edgar Allan Poe und in einem Essay porträtiert er Lenau. In den Gedichten über Masters und Poe versucht Kunert nichts zu verschönerm und doch spürt der Leser die Verehrung, die Kunert für diese Männer empfindet. Mit einer Mischung von Respektlosigkeit und Ehrfurcht skizziert er Bertolt Brecht:

\section{Erinnerung an Bertolt $B$.}

Meckerndes Gelächter. Unrhythmisches, unregelmäßiges Rucken des runden Kopfes: Spannung vor ständigem Start. Uberdruck in der grauen Kluft; das einzige Ventil: die Zigarre. Heitere Augen, kräftige Worte: Scheiße das schwächste. Zwei Lederlatschen, die mit ihm hin und her gingen. Inbrïnstig nichts glaubend. Beispielend. Von großzügigem Geiz. Fortdauer nur der Veränderung gestattet dieser letzte Heilige des Zweifels, der asketische Sybarit und Verkiinder der Wissenschaft der Kunst und der Kunst des Wissens. Manchmal: Im winzigen Sessel, der schaukeln konnte, in diesem seiner Erde nah, tief am hölzermen Boden: Die anderm, wir, auf erhöhten Plätzen. Und sahen zu ihm auf. Und er war nicht mehr da.24

Kunert beschreibt auch Catull, den Zeitgenossen Caesars, und dessen Lebensstil und gibt gleichzeitig einen respektlosen Einblick in die gesellschaftlichen Gegebenheiten seiner Epoche:

SHAKEHANDS, CATULL

Er nannte jedes Ding bei seinem Namen

Und machte sich nicht viel aus dem Geschrei.

Und seine Kunst war hochbeliebt bei allen Damen 
Von Rom bis in die ferne Lombardei.

Der große Caesar war ein größres Luder

Und biickte sich empor zu Macht und Ruhm. Jedweder Reiche und jedweder warme Bruder

Konnt Caesarn kaufen samt dem Heldentum.

Die Senatoren, reich durch ihre Huren,

Die sich verkauften der antiken Welt,

Und die von einem Freudenhaus zum anderm fuhren

und abkassierten das noch warme Geld.

Beherrschten Rom und seine Kolonien, Doch nicht Catull und dessen wilden Spott. Er zeigte seine Zeitgenossen auf den Knien Mit Venus ringend statt mit ihrem Gott.

Catull wies auf sie mit dem Zeigefinger (den man zu anderm Zwecken damals nahm). Denn er war mutig und war selbst ein guter Springer, Bevor er, fremd in fremder stadt, verkam.25 
DIE WENDUNG ZU KAFKA

In den sechziger Jahren ist eine Wendung zu Kafkas Stil in Kunerts Schriften zu bemerken. Diese Tatsache zieht die Kritik des DDR-Staates auf sich. Kafka wird offiziell abgelehnt und als negativer Einfluß betrachtet. Der Aufbau des Sozialismus erfordert Optimismus und Tatkraft, nicht Entfremdung und Skepsis. Aber es ist gerade das Gefühl der Entfremdung in einer bürokratischen und mechanisierten Welt, die Kunert auf Kafka zuriickgreifen läßt. In einem Gespräch mit Joachim Wal ther erklärt Kunert, warum er sich so vollständig von seiner früheren Didaktik abgewandt hat:

1.Das Didaktische lag in der Zeit, das war die Zeit nach 45, das war die Zeit, in der es völlig legitim war, daß alles, was man schrieb, Aufrufcharakter hatte. Aufruf und Anruf und Aufforderungscharakter, das war die Aufbauzeit, in der man das Gefühl hatte, man müsse den Leuten etwas zurufen, ganz direkt, man mïsse sie befeuern oder ermahnen. Da hat die Didaktik gebliiht, nur ist sie bei uns überständig geworden, denn sie wurde fortgeführt, obwohl sie sich eigentlich überlebt hatte. I

In dem gleichen Gespräch (S.82), bemerkt Kunert daß Kafka ein unglaublicher Realist sei, obwohl bei ihm sehr wenig konkret erscheine. Hier kann bereits die erste Paralelle zwischen Kafka und Kunert gezogen werden. Gefragt, welche literarischen Einflüsse es bei ihm gäbe, stellt Kunert an erste Stelle die reflektierende Prosa Kafkas (S.90) und fügt hinzu:

Nehmen wir mal Kafka: Das ist eine Schreibweise, in der sich viele offizielle Schreibweisen, auch ethnische Dinge, auch Dialektdinge mischen, das ist eine wenig persönliche Schreibweise, das 
ist eigentlich ein Sammelsurium, das verschmilzt. . .(S.91)

Diese Schreibweise trifft genauso auf Kunert zu, denn auch bei ihm findet man "eine wenig persönliche Schreibweise" und er bedient sich ebenfalls vieler Stilarten, die man eigentlich ein "Sammelsurium" nennen könnte. Die Sammlungen seiner Kurzprosa mit den Titeln Tagträume (1964) und Die Beerdigung findet in aller Stille statt (1968) sind die ersten, die den Einfluß Kafkas aufzeigen. Auch der Gedichtband Verkündigung des Wetters (1966) enthält verschiedene kafkaeske Gedichte, beispielsweise den folgenden Spruch:

IN DEN HERZKAMMERN DER ECHOS

Sitzen Beamte. Jeder Hilferuf hallt

Gestempelt zurïck.2

Das Gefihl der Machtlosigkeit, des Ausgesetztseins kommt hier klar zum Ausdruck. Jeder ist in gewissem Sinne ein Opfer der Bürokratie; aber der Bürokratie eines diktatorischen Staates ausgesetzt zu sein, kann nur der bewerten, der mit ihr zu leben hat. Fïr Kunert ist diese Bürokratie ein Teil des täglichen Lebens. Schon drei Jahre frïher hatte er dieses Thema in seinem viel kritisierten Gedicht "Unterschiede" (1963) behandelt:

\author{
Betrübt höre ich einen Namen aufrufen: \\ Nicht den meinigen. \\ Aufatmend \\ Höre ich einen Namen aufrufen: \\ Nicht den meinigen.3
}

Das Gefühl der Entfremdung, des Alleinseins und der Hoffnungslosigkeit ist auch in dem Gedicht, "Verkündigung des Wetters", zu finden: 
Auf unzeitgemäß verfertigtem Papier

Schreibe ich

Eine kleine fossile Wahrheit

In der Schrift

Welche vor den täglichen Weltuntergängen

Verständlich war. ${ }^{4}$

Als weiteres Beispiel kann auch die erste Strophe von "Notizen in Kreide" gelten:

Eingerichtet auf dem Gestirn

Unseres Schmerzes

Als Baracke. Aber fester denn jede Festung

Und dauernder. Ausgesetzt

Den bittersten Wettern. Ewiges Provisorium:

Ich. 5

Entfremdung, Isolierung und Angst drücken sich in "Sorgen" aus:

Der zu leben sich entschließt

Muß wissen

Warum er gestern zur Nachtzeit erwachte

Wohin er heute durch die Straßen geht

Wozu er morgen in seinem Zimmer

Die Wände mit weißem Kalk anstreicht.

War da ein Schrei?

Ist da ein Ziel?

Wird da Sicherheit sein?6

Jedoch der in der DDR herausgegebene Band, Geschichte der Literatur der Deutschen Demokratischen Republik (1976), kommentiert nicht zu den oben zitierten Gedichten. Statt dessen finden sich die folgenden Zeilen über Kunerts Dichtung der sechziger Jahre:

Insgesamt gesehen ist Kunerts Dichtung in der zweiten Hälfte der sechziger Jahre inhaltlich vielfältiger und formal reifer geworden. Sie fordert den Leser unerbittlich und nicht ohne moralischen Rigorismus auf, sich Rechenschaft über Verhältnisse und Verhaltensweisen zu geben, faschistischen Ungeist zu bekämpfen und die Voraussetzungen fïr eine im Sinne Brechts freundliche Welt ständig zu überprüfen.? 
Diese Beschreibung von Kunerts Dichtung paßt auf die fünfziger Jahre, aber sie ist durchaus ungültig, was die Mehrzahl seiner Gedichte der sechziger Jahre betrifft.

Kunerts Skepsis gegenüber technischer Fortschritte ist häufig zu bemerken. Er ist der Uberzeugung, daß die Technik nicht mit gesellschaftlich-humanitärem Fortschritt gleichzusetzen ist. Im Gegenteil, er sieht die Welt durch die überhandnehmende Technisierung gefährdet und durch die Mechanisierung entmenschlicht. Er sieht die Technik sogar als Hauptschuldträger in der Massenvernichtung von Menschen, sei es Hiroshima oder Auschwitz. Klaus Werner bemerkt dazu: "So nimmt zum Beispiel die Technik für Kunert dämonischen Charakter an, da er ihre ambivalenten Auswirkungen - man denke an die Ausnützung der Atomkraft - nicht mehr auf die gesellschaftliche Bedingtheit der jeweiligen Anwendungs- und Verwendungsweisen zurïckführt."8 Kunert sträubt sich gegen die Kluft, die er zwischen Technik und Humanität wachsen sieht. In verschiedenen Gedichten greift er dieses Thema auf. "Zwiefacher Monolog - kurzgeschlossen" zeigt seine Gedanken zur Entmenschlichung durch den Computer. In elegischer Sprache - er wählt Worte wie "O", "Ach" und "Wehe" - beklagt er den Verlust menschlicher Beziehungen, hervorgerufen durch diese elektronische Erfindung. 9

Und in einem anderen Gedicht drückt ex die Befïrchtung aus, da $\beta$ die fortgeschrittene Technik der Weltraumforschung den Menschen und seinen Planeten Erde einst als Opfer fordern könne:

\section{LAIKA}

In einer Kugel aus Metall, Dem besten, das wir besitzen, Fliegt Tag für Tag ein toter Hund Um unsre Erde 
Als Warnung,

Daß so einmal kreisen könnte

Jahr für Jahr um die Sonne,

Beladen mit einer toten Menschheit,

Der Planet Erde,

Der beste, den wir besitzen.10

Mit besonderer Unruhe steht der Schriftsteller einer technischen Exfindung gegenibber, die fïr die meisten Menschen nichts Bedrohliches oder Angsterregendes bedeutet, nämlich dem Telefon.11 Seine Kurzprosa "Das Telefon" (1972) gibt Einblick in diese Gedanken. Das Stuick beginnt mit dem Satz: "Es ist ein weitverbreiteter Irrtum, das Telefon sei ein Mittel zur Verständigung zwischen Menschen, die räumlich getrennt sind."12 Fiir Kunert ist dieser "kleine, schwarzglänzende Apparat" ein furchterregendes, fast dämonisches Objekt, "das uns in fröhlichen Minuten, stillen Stunden durch seine grelle Glocke in die Hölle unseres Gewissens reißt."13 Die Stimmen, die aus dem Telefon an sein Ohr dringen, haben einen "Ton von Bedrohlichkeit", "von Ubelwollen", "von Beleidigtsein" und "von tödlicher Gleichgïltigkeit". Was Kunert aber mit größerer Angst zu erfïllen scheint ist das Schweigen, das er in dem Apparat zu hören glaubt: "Wenn nach dem schrillen Klingelklang und nachdem man die Hördose ans Ohr gebracht, daraus nichts spricht als leise, rauschende Stille, aus welcher ïberspanntes Horchen ein schwaches Atmen vernehmen will, da öffnet sich der Abgrund in uns, und wir schauen suchend hinein, voller gräßlicher Erwartung, den Anlaß zu finden, der die stumme Bedrohung verursacht hat."14 Das Gefïhl der Angst, hervorgerufen durch Geräusche des Telefons - das schrille Klingeln und die bedrohlichen Stimmen - steigert sich, wenn die Stille eintritt. Diese Wechselbeziehung erinnert an Kafkas Empfindlichkeit gegenüber jeder Art von Geräuschen, die, abgelöst von Stille, eine Angstquelle bildeten. Jürg Honegger bemerkt im Falle Kafka: "Zur Angst- 
quelle des Lärms gehört auch diejenige der Stille. Wenn gar keine Geräusche mehr eine akustische Orientierung zulassen, kann diese Isolierung ebenso Angst aufbrechen lassen wie die Verhinderung jeglicher Konzentration durch stark empfundenen Lärm.15 Kunerts Angst jedoch konkretisiert sich, wird spezifisch und er drückt sie als ein tief empfundenes Schuldgefühl aus:

Da starren uns die verratenen Freunde an; anklagend heben ihre Hände diejenigen, die unsere Gleichgültigkeit im Elend ließ, deren Leben und Existenz wegen eines kleinen, unbedachten Fehlers ruiniert wurde, und denen wir nicht Hilfe liehen, unserer Feigheit wegen. Vertane Liebe, verspielte Chancen wirbeln auf wie welke Blätter. Und eigene Irrtümer, geringe Schwächen, sie wuchern ins Gigantische unter der Stummeit, die aus dem Hörer sickert: ein Gift, das schleichend weiterwirkt und gegen das in unseren wohlversorgten, blinkenden Apotheken kein Gegengift zu kaufen ist.16

In Gedichtform greift Kunert erneut das Thema Telefon auf. Während er in dem Prosastück dem Telefon bedrohliche und angsterregende Elemente beimißt, wird es in "Mein Aufenthalt" ein Mittel zur vergeblichen Suche nach Verständigung. Dieses Gedicht sollte aus politischer Sicht betrachtet werden. Ein starkes Gefühl der Isolierung kommt hier zum Ausdruck, das in strengem Kontrast zu seinen frïheren didaktisch-wegweisenden Gedanken steht.

Im europäischen Telefonnetz irrt meine Stimme umher: meinem Munde entwichen, kein Gehör gefunden, gefangen im Draht.

$\mathrm{Zu}$ Impulsen verwandelt, schwachen, und immer schwächer töne ich leise und unverständlich "Völker, hört die Signale..." in stillgelegten Membranen.

Wer mich empfänge 
und recht verstiinde und

fermamtlicherseits,

dem wäre ein Rufzeichen geworden,

ein Echo seiner eigenen Stummheit,

eine Antwort seiner Fraglosigkeit:

dem wäre ich

sehr verbunden.1?

Wenn man davon ausgeht, daß das „Telefonnetz" Kunerts literarische Wirkungsebene ist, dann wird seine Enttäuschung als politisch engagierter Dichter sichtbar. Er hat kein Gehör gefunden, denn er wurde mißverstanden. Seine Zuversicht auf Veränderung der condition humana wird abgelöst von einer resignierenden Traurigkeit: ....und immer schwächer töne ich/ leise und unverständlich..." In den letzten Zeilen deutet er an, daß es eine andere Möglichkeit gegeben hätte, wenn man ihn nur (fern)-amtlicherseits recht verstanden hätte. Der dunkle Ton dieses Gedichts wird durch das Wortspiel der letzten zwei Zeilen etwas erhellt: "dem wäre ich/sehr verbunden." Verbunden - im Sinne von Telefonverbindung, in Dankbarkeit verbunden oder brüderlich verbunden? Diese zwei Zeilen weisen auf Kunerts meisterhafte Handhabung der Ironie hin.

Auch sein anderthal bseitiges Prosastück "Der Kuß" zeigt klare, kafkaeske Züge. Eine alltägliche Situation wird geschildert: Einem Dichter, der soeben eine Lesung beendet hat, wird gratuliert und zugejubelt. Der stellvertretende Oberstadtrat ist der erste Gratulant. Bereits hier endet das Alltägliche: "Ein Paar schwarzbeärmelte Greifer umschlangen ihn. Feuchte Lippen drückten sich in sein Gesicht."18 Immer mehr Greifer, die sich nur durch verschiedene Stoffarten unterscheiden, umschlingen den Dichter und zahllose Münder, die kannibalisch wirken, bedecken ihn mit Küssen. Machtlos ist er Armen; Mündern und Händen ausgeliefert. In dieser orgiastischen Anbetung findet der Dichter seinen Tod. 
Mit schwindendem Bewußtsein merkte der allgemein geherzte derart dem Vorgang entrückt, als beträfe es einen andern -, wie untertänig zitternde Hände ihn der Hose entledigten, ehe inm die Luft endgiiltig wegblieb und er an einer rumpsteakstarken liebevollen Zunge erstickte, die nach Zigarre schmeckte, und deren anormaler Länge sein allerletztes Staunen galt. (S.88)

Zwei weitere Gedichte müssen angeführt werden, die eine Verbindung mit Kafka andeuten. Beide entstammen dem 1977 in der Bundesrepublik erschienenen Unterwegs nach Utopia. Kunert verleiht beiden Gedichten den gleichen Titel und unterscheidet sie nur durch römische Ziffern. Das erste Gedicht, "Neues vom Amt I", greift erneut das Thema der Bürokratie in ihrer Willkürlichkeit und Entmenschlichung auf:

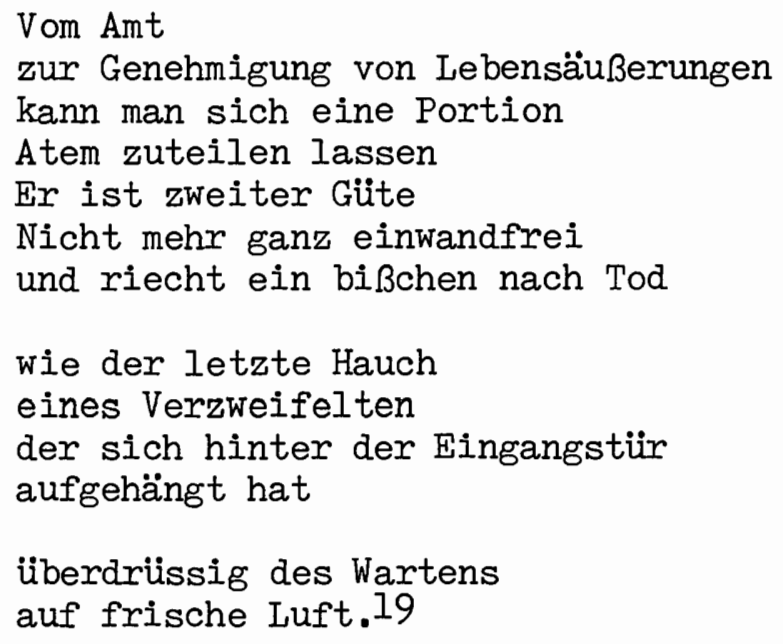

Das zweite Gedicht, "Neues vom Amt III",20 ist ein persönlicher Hinweis, denn das Pronomen „ihm" muß als "Günter Kunert" gelesen werden:

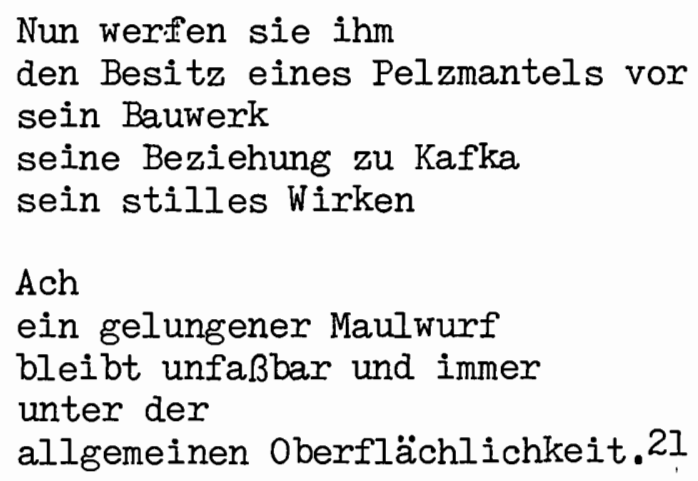


Kunert zieht staatliche Kritik auf sich, da er seiner Frau einen Pelzmantel kauft, sein ehemals ausgebombtes Haus renovieren läßt, Kafka bewundert und ungeachtet aller negativen Einflüsse seinem Schreiben nachgeht. Diese beiden Gedichte erschienen in der Bundesrepublik und werden..wohl kaum vom zuständigen Amt der DDR gebilligt werden können.

Die kafkaesken Zïge in Kunerts Werken nehmen in den späten sechziger und siebziger Jahren zu. Die in der DDR verlegte Geschichte der Literatur der Deutschen Demokratischen Republik ignoriert weiterhin diese Entwicklung, selbst nachdem das Gedicht "Interfragmentarium (zu Franz K.'s Werk)" erschien.22 Dieses Gedicht besteht aus Gedankenfragmenten, die Kunert zu einem kafkaesken Bild werden läßt:

Aus seinem Bett erhebt sich ungestärkt Der Schläfer: Verstohlen Blickt er um sich ob auch Im Zimmer nichts von seinem Traum verblieb.

2

Wie sieht den Erwachten Heute der Spiegel an? Hat der Schon Verdacht geschöpft?

3

Von der Decke sinkt an einem Faden

(Wer wei $\beta$ denn was fiir einem)

Eine Spinne (wer wei $\beta$ schon welcher Art)

Auf den

Am Tisch Sitzenden herab zu hören was

Er denkt.

4

Die Klingel gellt. Das Telefon. Die Wohnungstiur. Das Haustor. Die Hinrichtung. Die ganze Welt. Sie bimmelt rasend schrillt und schreit Und gellt - und stirbt Lautlos mit einem Schlag. 
Das Telefon ist stumm. Dickes gemeines

Schweigen steigt aus der Muschel. Vor dem

Hause aber steht niemand der fürchterlich graue

Niemand. Vor der Wohnungstuir wirft

Keiner einen Schatten und atmet

Keiner lauernd.

6

Stille. Kasemattenstille. Felsenkellerstille. Manchmal unterbrochen von Geräusch: Dumpf

Geht über Decken und Stiegen ein Stampfen.

Ein Schreiten über Treppen und Böden durch

Flure und Kammerm ein Schritt: jener

Der Gewalt die viele Namen trägt.

$\mathrm{Zu}$ viele.

7

In seinem Bette liegt schon

Sterbensmatt nach einem lebenslangen Tag

Der einen Tag aufs neue überlebt

Mit letzter Kraft und einem Lächeln das

In die Fratze eingefressen

Wie ekelhafter Aussatz ist und lauscht. Und

Lauscht.

8

Und lauscht.23

In diesem Gedicht, das stark an "Die Verwandlung" erinnert, übertragen sich angsterregende und bedrohliche Elemente des Traumes auf die Wirklichkeit des Erwachten. In dieser Wirklichkeit fühlt er sich beobachtet, belauscht, verfolgt und schließlich hoffnungslos gefangen. Ist dieses Gedicht nun Kunerts Versuch, Kafkas Gedankenwelt zu erfassen und zu reflektieren oder fühlt er eine Verwandtschaft zu dessen angsterfülltem Leben? Alexander Abusch stellt sich diese Frage nicht. Er interpretiert "Interfragmentarium" als "eine Apologie Franz Kafkas" und beschuldigt Kunert einer "bürgerlichen Philosophie der Lebensangst, der Isoliertheit des Individuums in einer ihm feindlichen Umwelt."24 Zusätzlich spricht Abusch von Kunerts 
"schrankenlosem Subjektivismus", der sich in einigen Gedichten zeigt und bemerkt, ". . . daß Genosse Kunert das Wesen unseres sozialistischen Weltund Menschenbildes nicht begreift."25 Abuschs besondere Kritik gilt der vorletzten Zeile der sechsten Strophe: ". . heute wird Kunerts Gedicht, mit seinen doppeldeutigen Zeilen gegen 'die Gewalt, die viele Namen trägt. Zu viele' auch als gegen die Gewalt unserer sozialistischen Arbeiter-undBauern-Macht gerichtet gedeutet."26 Abschließend stellt Abusch diese Frage an den Dichter:

Ich frage Gïnter Kunert: Wollen Sie noch ein Dichter unserer Republik und gar ein Dichter unserer Partei sein? Wissen Sie nicht, wo die völlige Preisgabe unseres Weltbildes des sozialistischen Humanismus, unserer weltverändernden und weltbefreienden Ideen beginnt?

Es ist die Frage an den Genossen und Dichter, der sich das sehr genau überlegen sollte. Er ist damit vor die größte geistige Entscheidung seines Lebens gestellt: nämlich zuruickzukehren aus den hoffnungslosen grauen Gefilden von Kafka und Benn in die lebensstarke Welt des umfassenden Aufbaus des Sozialismus.2?

Da für Kunert das Grundmotiv der Lyrik in seiner gegenwärtigen Wirklichkeit liegt, kann auch "Interfragmentarium" als Reflektion derselben betrachtet werden. Somit hat sich der Dichter weit von den frïhen Lehrund Warngedichten entfernt, die in den fünfziger Jahren ein Hauptelement seiner gegenwärtigen Wirklichkeit waren. 


\section{III}

\section{NATURBILD ALS PARABEL}

Elemente der Natur erscheinen oft in Kunerts Lyrik und Prosa, und zwar vor allem Bäume und Wasser. Ein erster Hinweis ist in seinem „Rekonstruktionsversuch eines fernen Augenblicks" zu finden. Den Anreiz zu dieser Beschreibung, die er als siebzehnjähriger niederschreibt, bildet eine Kastanie. "Ich blicke hinaus zum Hof: ihn fillt eine riesige Kastanie aus, blühend, gespreizte Blätter wie Tatzen, im Umriß ähnlich den versteinerten Abdrücken verschwundener Geschöpfe."l Fỉr Kunert geht der Naturbereich nicht von der Naturauffassung in der Romantik aus, die verheimlicht und die Naturelemente mysteriös werden läßt, sondern er weist auf die Natur hin - die für ihn fast immer personifiziert ist - um gesellschaftliche Gegebenheiten auszudruicken. Eine blühende Kastanie hat nichts Bedrohliches an sich; aber für Kunert, ein Jahr nach dem Krieg, bedeuten die gespreizten Blätter Tatzen verschwundener Geschöpfe, versteinert zwar, aber immer noch bedrohlich, grausam und unvergeßlich. Die Vergangenheit greift immer stark auf seine Gegenwart über.

Der Baum als Symbol einer schrecklichen Vergangenheit erscheint in "Liebsame Beschäftigung". Hier nehmen die Bäume die Form schwarzer Skelette an, die den Himmel tragen.

\footnotetext{
Abends

Wenn in den Straßen der Städte Das Licht stirbt und schwarze Skelette Zeitweilig "Baum" genannt

Den Himmel tragen

Erwachen die toten Soldaten.
} 
Unter dem naßglänzenden Pflaster

Marschieren sie dahin.

In den Straßen fielen sie

Einstmals Freund und Feind

Ubergossen einander mit brennendem Benzin

Jagten sich Reihen leuchtender Geschosse

In den Leib.

Sie marschieren unter dem Pflaster

Wenn die Städte still sind

Daß ihr sie hört.

Ruhelos

$\mathrm{Da}$ ihr dort oben in euern Häuserm

Bahnen

Autos

Auf den Brücken und Türmen beschäftigt seid

Nur mit vergessen

Vergessen

Vergessen.2

Diese Bäume halten den Himmel über den Straßen, nachdem das Licht gestorben ist. In dieser Dunkelheit, die den geschäftigen, ablenkenden Alltag zum Schweigen brịgt, erinnert sich Kunert an eine blutige Vergangenheit, die noch immer seine Gegenwart ist. Er scheint der Einzige zu sein, der die toten Soldaten unter dem Pflaster marschieren hört. Er fühlt ihre Anklage an die Uberlebenden, die nur damit beschäftigt sind, zu vergessen. Er appelliert an die tauben Uberlebenden, das Erwachen der toten Soldaten zu hören. Sein Warnruf bleibt jedoch ungehört. Bäume, die als schwarze Skelette warnend die Vergangenheit heraufbeschwören, bleiben ungesehen von denen, fü die Kunert die Mahnung bestimmt hat. Seine Hoffnungslosigkeit und Resignation spiegeln sich in den letzten drei Zeilen durch die monotone Wiederholung des Wortes "vergessen" wider.

In dem folgenden Gedicht werden Resignation und Hoffnungslosigkeit abgelöst von Aktivität und skeptischer Hoffnung. "Als ich ein Baum war" (1961) erweitert die Symbolik des Baumes, indem Kunert ihn nicht als dun- 
kel-warmendes Objekt darstellt, sondern ihm ein aktiveres Eingreifen ermöglicht. Die Anregung zu diesem Rollengedicht erhielt er von Catull, der sich, als Dichter, ebenfalls mit einem Baum verglich.3 Obwohl die zugrundeliegende Thematik ähnlich ist, ist die Philosophie Kunerts der von Catull entgegengesetzt. Catull beginnt sein Gedicht mit der bereits stattgefundenen Transformation des Baumes und weist darauf hin, daß das viel bewunderte Schiff einmal ein Baum gewesen war:

Phaselus ille, quem uidetis, hospites, ait fuisse nauium celerrimus, neque ullius natantis impetum trabis nequisse praeterire, siue palmulis opus foret volare siue linteo.4

In Kunerts Gedicht dagegen beginnt der Baum seine Existenz in Unschuld und Gleichmaß:
Als ich noch ein Baum gewesen, Hielt ich mich mit Wurzeln
In der guten Erde fest Und liebte die Erde, weil diese Mich aus sich kommen läßt.5

Bei Catull steht ein Schiff, das die Ozeane besegelt und das weder von Stuirmen, noch von mißgünstigen Göttern aufgehalten werden kann, für den Dichter. Catulls verwandelter Baum beendet seine Lebensfahrt unbeirrt und erreicht einen sicheren Hafen in einer sturmfreien Bucht:

$$
\begin{aligned}
& \text {... neque ulla uota litoralibus deis } \\
& \text { sibi esse facta, cum ueniret a mari } \\
& \text { nouissimo hunc ad usque limpidum lacum... }
\end{aligned}
$$

Der Baum in Kunerts Gedicht wächst über seine schützende, natürliche Umwelt hinaus. Obwohl Catull sich in seinem Gedicht selbst verkörperte, 
spricht er doch in der dritten Person. Kunerts Ich-Form unterstreicht die Personifikation des Baumes:

Weil ich aufwuchs, ragte ich endlich

Uber Sträucher und Büsche hinaus:

So ward die Welt größer und weiter, Zeigte Gaskammern, Galgen und Zellen Und sah wie ein Schlachthof aus.

Kunerts Baum kann nicht unbeirrt sein Wachstum fortsetzen. Durch die Größe, die ihn über alles hinwegsehen läßt, entdeckt er die Mißstände seiner Welt. Kunert verändert die Form seines Baumes, so wie Catull den Baum in ein Schiff transformiert, und läßt ihn nicht länger Baum sein. Während Catull dem Baum eine konkrete Form gibt, ist bei Kunert die neue Form des Baumes nur angedeutet, läßt den Leser aber vermuten, daß es sich um eine menschliche handelt.
Damals habe ich mich entschlossen, Nicht länger Baum mehr zu sein; Und zog mich aus dem Boden mit Macht Und mischte mich in das Leben der Menschen Ganz unauffällig ein.

Catulls Baum landet im sicheren Hafen; es hat die Stürme überstanden. Fïr Kunert gibt es keinen sicheren Ort. Entwurzelt versucht er, in das Leben der Menschen einzugreifen, mit der Hoffnung, daß sein Opfer nicht unerkannt bleibe. Catull, zurückblickend, zeigt allen Widerständen zum Trotz, daß das Schiff im sicheren Hafen landet. Kunert läßt den Baum in seiner neuen Form - durch das von inm gebrachte Opfer aktiv eingreifen.

Hoffe heimlich, sie erkannten Am Blut, da $\beta$ an den Wurzeln an mir blieb, $\mathrm{Da} ß$ ihnen zu Hilfe sich losgerissen

Ein Baum: den der Anblick der Kämpfe

Aus den friedlichen Wäldern trieb. (S.30) 
Der Gebrauch von Vergleichen, die Naturelemente einschließen, ist auch in Kunerts späteren Werken unverkennbar. Er verstärkt diese Anwendung in den folgenden Beispielen, in denen sein parabolischer Stil zu beobachten ist. So wie der "Baum", so erscheint das Naturelement "Wasser" häufig in Kunerts Werken. Wenn man davon ausgeht, daß die Parabel eine Geschichte erzählt, die aus der Wirklichkeitsebene auf eine Bedeutungsebene übertragen werden muß, so kann gezeigt werden, daß sich diese Definition bei Kunerts Gedicht "Wie ich ein Fisch wurde" bewahrheitet. Die verschlüsselte Bedeutung ermöglicht es Kunert, dieses Gedicht zu veröffentlichen, obwohl es erst von den Rezensenten des Staates genehmigt werden mußte. Es erschien zum ersten Mal in Sinn und Form im Jahre 1961. Es wird angenommen, daß dieses Gedicht nach einem Augustsonntag des Jahres 1961 entstanden ist. Das genaue Datum läßt sich nicht dokumentieren. Kunert beginnt die erste Zeile mit einem präzisen, wenn auch fiktivem Datum. Das spezifische Datum einer Katastrophe prägt sich in die Erinnerung eines jeden, der davon betroffen wird. Wenn man davon ausgeht, daß dieses Ereignis die Errichtung der Mauer ist, dann ist anzunehmen, daß Kunert persönlich betroffen war. Das kann eine Erklärung dafür sein, daß Kunert diesem Gedicht eine für ihn ungewöhnliche Form gibt. Er gebraucht gereimte, wenn auch nicht regelmäßige Verse, die stark von dem unpersönlichen, lakonischen Stil abweichen, der sonst für Kunert typisch ist. Die Rhythmik, meist Trochäen, gibt jedem Versfuß die Bewegung des anschwellenden Wassers, das sich unaufhaltsam ausbreitet. Zuerst sind es nur die Flüsse, die sich'aus ihren Betten heben und für einige ist noch Zeit, sich auf höhere Ebenen zu retten:

Am 27. Mai um drei Uhr hoben sich aus ihren Betten Die Flüsse der Erde, und sie breiteten sich aus 
Uber das belebte Land. Um sich zu retten

Liefen oder fuhren die Bewohner zu den Bergen raus. 6

Eine Paralelle kann hier gezogen werden zu den politisch Hellhörigen, die die noch bestehende Möglichkeit einer Flucht in den Westen wahrnahmen. Zweifellos gehört auch Kunert zu den politisch Hellhörigen, aber bis zu einem gewissen Zeitpunkt befürchtete er nie, daß sich die weitere Entwicklung auch auf ihn auswirken könnte. Unaufhaltsam kommt jedoch diese Entwicklung auf alle zu:

Als nachdem die Flüsse furchtbar aufgestanden, Schoben sich die Ozeane donnernd übern Strand, Und sie schluckten alles das was noch vorhanden, Ohne Unterschied, und das war allerhand.

"Ohne Unterschied, und das war allerhand." Sein Erstaunen über die Ausmaße der Katastrophe hält aber nicht lange an, denn er und die anderen $\mathrm{Zu}$ rückgebliebenen müssen sich mit dem neuen Element befassen. Diejenigen, die sich von der Flut mittreiben lassen, versuchen auf ihre Weise zu überleben:

Eine Weile konnten wir noch auf dem Wasser schwimmen, Doch dann sackte einer nach dem anderen ab. Manche sangen noch ein Lied und ihre schrillen Stimmen Folgten den Ertrinkenden ins nasse Grab.

Kunert deutet an, da $\beta$ man sich völlig dem neuen Element anpassen muß, um zu überleben:

Kurz bevor die letzten Kräfte mich verließen, Fiel mir ein, was man mich einst gelehrt: Nur wer sich verändert, den wird nicht verdrießen Die Veränderung, die seine Welt erfährt.

Leben heißt: Sich ohne Ende wandeln. Wer am Alten hängt, der wird nicht alt. 
So entschloß ich mich sofort zu handeln, Und das Wasser schien mir nicht mehr kalt.

Meine Arme dehnten sich zu breiten Flossen,

Grïne Schuppen wuchsen auf mir ohne Hast;

Als das Wasser mir auch noch den Mund verschlossen,

War dem neuen Element ich angepaßt.

"Die Veränderung, die seine Welt erfährt" muß auch Kunert erfahren. Diese Erkenntnis enthält auch bittere Selbstanklage. Die Veränderung zwingt ihn in eine neue Form, die es ihm ermöglicht, in dem neuen Element zu existieren. Nachdem das Wasser ihm den Mund verschlossen hat, kann er sich träge gleiten lassen. Er stemmt sich nicht gegen die unaufhaltsame Flut. Es ist eine von ihm selbst getroffene Wahl, die ihn in retrospektiver Sicht zu beschämen scheint:

Lasse mich durch dunkle Tiefen träge gleiten, Und ich spuire nichts von Wellen oder Wind, Aber fürchte jetzt die Trockenheiten, Und daß einst das Wasser wiederum verrinnt.

Er stellt die Frage, ob der Wunsch zu überleben - und das dadurch notwendige Sich-Anpassen - fundamentale, menschliche Schwächen sind. Offensichtlich beantwortet er diese Frage, indem er sich selbst beschuldigt, dieser Schwäche unterlegen zu sein. Er befürchtet zukünftige Veränderungen, denen er sich wiederum anzupassen haben wird. Er scheint auch zu sagen, daß er sich bewußt ist, durch diese Schwäche auf eine menschenunwürdige Tiefe herabgesunken zu sein:

Denn aufs neue wieder Mensch zu werden, Wenn man's lange Zeit nicht mehr gewesen ist, Das ist schwer für unsereins auf Erden, Weil das Menschsein sich so leicht vergißt.

Das gleiche Thema greift Kunert in seinem kurzen Prosastick .,Sint- 
flut" erneut auf.7 Obwohl das Thema identisch ist, hat sich das Grundgefühl stark geändert. Was man in seinem parabolischen Gedicht als teilweise Selbstanklage erkennen kann, zeigt sich in "Sintflut" als bittere Ironie und mehr nach außen gerichtete Anklage. In "Wie ich ein Fisch wurde" ist trotz der großen Katastrophe eine unausgesprochene Hoffnung zu finden, daß das "wieder Menschsein" nicht ausgeschlossen ist. In "Sintflut" ist keine solche Hoffnung zu finden. Das Prosastiick reflektiert die progressive Entwicklung der politischen Lage vor und nach Errichtung der Mauer: "Die Sintflut beginnt unmerklich. Vorerst steigen die Fluisse um wenige Zentimeter. Es regnet nicht einmal häufiger als sonst, aber anhaltender."8 Kunert stellt hier dar, wie sich die politische Krise scheinbar unmerklich entwickelte. Die politische Stimmung hatte seit der Entstehung der DDR ständig hin und her geschwankt. Die Bevölkerung hatte sich daran gewöhnt, in einer Wechselbeziehung von strengster politischer Einschränkung und sogenanntem "Tauwetter" der nachstalinistischen Liberalisierung zu existieren. Kunert gebraucht in "Sintflut" meisterhaft seine Technik des "Zwischen-den-Zeilen-Schreibens", bestimmt für den Leser, der an das "Zwischen-den-Zeilen-Lesen" gewöhnt ist. "Die Industrie wird mehr Regenschirme herstellen, mehr Gummistiefel, doch das sind die einzigen Maßnahmen, die man trifft." Der Staat versucht, die Folgen zu mildern, aber um die eigentliche Ursache kümmert er sich nicht. "Ein paar Wetterkundler weisen auf die Merkwürdigkeiten im Wetterablauf hin, nur versteht ihre wissenschaftliche Sprache kein Mensch, und ihre Entdeckung wird sofort wieder vergessen." Hier scheint Kunert sich wieder direkt auf die politisch Hellhörigen zu beziehen, die die Katastrophe voraussehen und die den Versuch machen, ihre Mitbürger darauf aufmerksam zu machen. Die Anklage in den folgenden Zeilen kann Kunert notgedrungen nur schwach an- 
deuten: "Wenn die Flüsse über die Ufer steigen, wird man es dem jeweiligen Landesfeind ankreiden, doch weil die Nachrichtenübermittlung nicht zu verhindern ist, erfährt alle Welt von der synchronen Uberschwemmung vieler Gebiete der Erde." Was der DDR-Staat seinen Bïrgern zu Ohren kommen läßt, die sich jetzt der bevorstehenden Krise bewußt sind, sind Anklagen gegen den aggressiven Westen, vor dem die DDR-Biirger bewahrt werden müssen. Da Nachrichtenübermittlung aber nicht zu verhindern ist, erfahren bald alle, welche politische Veränderung ihnen droht. Kunert illustriert diese Veränderung, indem er Tümpel, Teiche und Seen zu kleinen Meeren werden läßt. Die Krise ist unübersehbar, obwohl "hauptsächlich von einer vorïbergehenden Krise der Witterung" gesprochen wird.8 Heimlich werden nun Fachleute aus Venedig zitiert, deren Erfahrungen das wäßriger werdende Leben erleichtern sollen. Wenn man statt "Venedig" aber "Moskau" liest, so wird es dem Leser klar, daß es sich hier nicht um Fachleute aus dem Gebiet der Architektur handelt. Der neue Staat soll den Vorbilderm anderer, schon entstandener sozialistischen Staaten angepaßt werden. Der folgende Kommentar, einem Abschnitt der Geschichte der Literatur der Deutschen Demokratischen Republik entnommen, zeigt die Paralellen auf:

Die Gestaltung der entwickelten sozialistischen Gesellschaft, die den kommunistischen Aufbau vorbereitet, begann zuerst in der Sow jetunion; in den meisten anderen sozialistischen Ländern Europas setzte dieser Prozeß im Laufe der sechziger Jahre ein. . . Die Schließung der Staatsgrenze der DDR gegenüber Westberlins im August 1961 machte auch den Störungen ein Ende, die von dort aus das Wirtschaftsleben der DDR schwer geschädigt hatten.9

Die Angst vor dem Unabwendbaren reflektiert Kunert, wenn er das Wasser steigen läßt, da es trotz beruhigender Zeitungsartikel nicht aufzu- 
halten ist. Die Katastrophe der politischen Uberschwemmung ist Realität geworden. Man ist sich in der DDR Kunerts parabolischer Behandlung von Katastrophen - vergangener und gegenwärtiger - kritisch bewußt. In der Geschichte der Literatur der Deutschen Demokratischen Republik heißt es: "Der Autor vermag menschliche Haltungen angesichts drohender Katastrophen überzeugender und anschaulicher darzustellen als produktive und weiterführende."10

In den letzten zwei Abschnitten der "Sintflut" formuliert Kunert eine bittere Anklage gegen Ost und West. Die erste Anklage richtet er gegen den Westen, der, falsche Hoffnungen machend, letzten Endes nicht die Katastrophe aufhält: „Hubschrauber fliegen über die aus den Wellen ragenden Reste und werfen Flugblätter $a b$, des Inhalts, daß alles getan werde, das Unglück abzuwenden. Gläubig lesen die Ertrinkenden die druckfeuchten Blätter."ll

Die an Kunerts eigenen Staat gerichtete Anklage ist nicht nur auf die eigentliche Errichtung der Mauer zuriickzuführen, sondern auch auf die zukinftigen Auswirkungen dieser Maßnahme. Er, der als Künstler an dem Aufbau seines sozialistischen Staates mitgewirkt hatte, fiuhlt sich einerseits mitverantwortlich und andrerseits von diesem Staat hintergangen. Die Sintflut hat ihn, wie alle anderen, betroffen: "Das zu verheimlichen, wird allen Beteiligten wichtiger sein, als in dem zunehmenden Regen, in den schwelgenden Bächen, den andauernden Wolken die beginnende Katastrophe zu erkennen." 12

Hoffnung auf die Zukunft, auf positive Veränderungen, auf das Zuriickweichen des Wassers widerlegt Kunert in totaler Resignation: "Gewiß: Fïr eine weitere Sintflut würde man viel besser vorbereitet sein, wenn man nicht schon bei der ersten untergegangen wäre." (S.63) 
Kunert wird von John Flores als der wichtigste Repräsentant der DDR Literatur bezeichnet. Er weist darauf hin, daß Kunerts Schreiben die ganze Zeitspanne der Existenz der DDR und ihrer Literatur einschließt. Flores kommentiert weiter:

He may never have proclaimed allegiance to his country as forthrightly and loudly as others, and his reaction to its brutality has been unusually radical. But as a poet he has grown with it, and the hopes and disappointments expressed in his poetry were inspired by the accomplishments and the failures of East German society. 13

Gerade um das Versagen des DDR-Staates zu kritisieren, bedient sich Kunert der parabolischen Schreibweise. Die Gefährlichkeit dieser Parabeln wird von der Partei erkannt, wie ein 1964 geschriebener Kommentar beweist:

In vielen Fällen wird jedoch der spezifische Stein des Anstoßes nicht sichtbar, die Kritik politischer oder moralischer Erscheinungen wird ihrer historischen und sozialen Konkretheit entkleidet. Dadurch tendiert das Parabelgedicht zur Vieldeutigkeit der Aussage und Auslegbarkeit. Häufig ist damit eine registrierendbelehrende Haltung verbunden, die die Möglichkeiten der Aktivierung und des produktiven Eingreifens durch das Gedicht einschränkt. Beide Momente finden wir in jüngster Zeit in den Parabelgedichten Gïnter Kunerts. 14 
STADTBESCHREIBUNGEN

Stadtbeschreibungen sind ein immer wieder erscheinendes Element in Kunerts Lyrik und Prosa. Die Stadt, mit der er sich am häufigsten befaßt, ist seine Heimatstadt Berlin. Er betrachtet die Stadt als Ganzes oder er konzentriert sich auf eine bestimmte Gegend und eine bestimmte Straße. Oft ist das Thema jedoch ein spezifisches Haus, dessen Inneres und Außeres er bis auf die kleinsten Einzelheiten beschreibt. Immer sind diese Beschreibungen eng mit der Vergangenheit verbunden, die er ohne Sentimentalität und Nostalgie zu rekonstruieren versucht. Der Band, Tagträume in Berlin und andernorts (1972), enthält mehrere Beispiele dieser Beschreibungen in Form von Kurzprosa.1 Für Kunert verbinden sich die Vergangenheit einer Stadt und deren Häuser mit der Vergangenheit des individuellen Menschen. In einem persönlichen Gespräch im September 1975 drückte er jedoch die Befürchtung aus, daß der Verlust dieser Vergangenheit unaufhaltsam sei. Den Grund dafür sieht er in dem Wiederaufbau Berlins, durch den ganze Straßenzüge alter Häuser durch Betonkonstruktionen ersetzt werden. Diesem Wiederaufbau fallen sogar Gebäude zum Opfer, die man mit einiger Restaurierung hätte erhalten können und sollen. Auf die Frage, ob das nicht in allen deutschen Städten der Fall sei, folgte die Antwort, daß keine Stadt auf Erden so traditionsfeindlich sei wie Berlin und daß sich diese Tendenz auch auf dem Gebiet der Architektur bemerkbar mache. In "Häuser an der Spree" (S.147) erläutert Kunert seine Affinität zu den alten Gebäuden der Stadt: 
$\mathrm{Zu}$ mir sprechen die Steine. Wenn auch nicht alle. Aber es sind auch nicht alle Menschen befähigt, sich auszudruicken. Die grauen Großblöcke, die frischen jungen Ziegel sagen mir gar nichts, nur die von Erfahrung brüchigen, die vom Dasein lädierten, die von neuem und unserem Leben bereits befallenen, bemoosten, überwucherten. So stehe ich vorm Gemäuer alter Berliner Häuser, vor den Altersflecken fehlenden Putzes, streifig von herabrinnendem Wasser, von Granatsplittern noch immer versehrt und von Kugeleinschlägen, innen geräumt und abrißbereit, da auch an ihrerstatt der viereckige Beton ersetzen soll, was unersetzlich ist: die Zeichen gelebten Lebens.

In "Haltungen zu einer Stadt I" (S.I48) jedoch ist mehr als Affinität zu erkennen. Hier gleichen seine Betrachtungen einer Liebeserklärung, in der die Stadt fast personifiziert wird. Kunert bekennt sich zu seiner Stadt, obwohl er sie - wie er in der ersten Zeile anfuhrt - eigentlich nicht kennt, aber dennoch auf ewig in ihr leben wird. Die Resonanz eines Treueschwurs unterstreicht er im letzten Paragraphen, in dem er seine Liebe zu der Stadt, die er so wenig kennt, mit menschlicher Liebe vergleicht. Er drückt den Gedanken aus, daß gerade das Unwissen über einen geliebten Menschen die Liebe $\mathrm{zu}$ ihm vertieft. Das Geheimnisvolle, sei es nun in den Mauerm einer alten Stadt oder in einem Menschen zu finden, ist das verbindende Element.

In „Haltungen zu einer Stadt II" (S.I49) macht er die personifizierte Natur zu einem Teil des Stadtbildes. Die frühe Herbstsonne hat eine "große Eindringlichkeit", eine "Helle", die alles leichter macht, die das Tägliche und die Vergangenheit vergessen läßt. Das Gefühl der Freiheit und der Geborgenheit stehen in seltsamem Kontrast zueinander, den er aber durch die letzten beiden Sätze abschwächt. Sie zeigen die fïr Kunert oft so typische Skepsis: "Da geht man frei. Solange das Leuchten anhält." In "Haltungen zu einer Stadt III" (S.I50) erscheint erneut das Element des Geheimnisvollen, das sich in den alten Straßen und Mauern ver- 
birgt, die wiederum fast menschliche Zïge erhalten. Der befürchtete VerIust dieser Straßen und Mauern, die ihr Geheimnis nicht preisgeben, ist hier ebenfalls zu spïren. Noch sind sie da; der ergebene, zu oft getretene Asphalt, die Fenster, die verschlossen auf ihn hinabblicken und die Tore, die sich manchmal öffnen „als wollten sie endlich, endlich ein wörtchen ihres Wissens preisgeben." Durch das Attribut des Wissens, das Kunert ihnen verleiht, erscheinen die Gebäude überlegen. Sie erkennen, was ihnen bevorsteht und "warten und warten; warten mit großer Geduld. Obwohl sie von uns alles wissen." In den letzten vier Zeilen besitzen die alten Mauern nicht nur Wissen, sondern sogar elementare Weisheit, deren unaufhaltsamen Verlust Kunert voraussieht: "Daher füchte ich den Tag, da die Häuser urplötzlich in ihre Bestandteile zerfallen und über uns zusammen. Und daß sichtbar wird: Jeder Ziegel war der Stein der Weisen."

In der Prosasammlung Ortsangaben (1974) ist ein Stück enthalten, das weiteren Einblick in das Kunertsche Stadtbild gibt. "Berliner Gemäuer" zeigt aber auch Kunerts Rückkehr in die Vergangenheit seiner Familie, deren Erinnerung durch die alten Häuser wachgerufen wird. Indem er in den Stadtteil seiner Kindheit zurückkehrt, stellt er fest, "daß gerade hierorts das verbaute verbrauchte Gestein ganz besonders redselig erscheint."2 Als er in eins der für Berlin so typischen Mietshäuser eintritt, bemerkt er, daß diese Gemäuer "ihre eigene unverwechselbare Ausdünstung, eine körperhafte Losung" haben. Das Leben, das Epochen hindurch in ihren Mauern waltete, hat sie selber verlebendigt. (S.101) Kunerts Weg in die Vergangenheit führt ihn über einen Hinterhof mit moosig grünem Katzenkopfpflaster. Der Leser hat bis zu diesem Punkt das Gefühl, daß Kunert sich der Wohnung seiner Kindheit nähert. Er hat bereits von der Dorotheenstadt und der Chausseestraße gesprochen, wo er geboren wurde 
und wo eben dieser Hinterhof liegt. Er erreicht eine Stiege, die zu einer Wohnung führt, von der der Leser immer noch annimmt, daß sie Kunerts frühere gewesen sei. Ohne einen Namen zu nennen, beweist er aber, da $\beta$ er den Leser irregeführt hat: „..., um dort eine rechtens so geheißene Stiege zu einer Wohnung hinaufzusteigen, von der aus man auf den Dorotheenstädtischen Friedhof hinabblickte, auf welchen der Wohnungsinhaber nach einiger Zeit verzog; dort liegt er jetzt gegenüber Fichte und Hegel und hat für seine dialektischen Späße die richtige Gesellschaft." (S.103) Der "Wohnungsinhaber" ist zweifellos Kunerts frühes Vorbild Bertolt Brecht.

Sein Weg führt ihn durch andere Hinterhöfe, die sich kaum voneinander unterscheiden und befindet sich plötzlich in einem Hinterhof, der einem seiner Kindheit gleicht. "Ich stand in einem engen unregelmäßigen Rechteck, mit einem Deja-vu, wie es jeder einmal erlebt hat, erblickt er zum ersten Male etwas, das ihm so bekannt vorkommt, als kenne er es von jeher." (S.105) In allen Einzelheiten sieht er den Hof und das dazugehörige Haus seiner Großeltern. Er befindet sich in einer völlig fremden Umgebung, aber dennoch erkennt er jeden Stein. Haus und Hof seiner Großeltern waren vor langer Zeit in Flammen aufgegangen und nun steht er plötzlich vor einem Gebäude, das mit dem seiner Kindheit identisch zu sein scheint. Liebevoll beschreibt er die Fassade des Hauses mit ihrem abbröckelnden Putz und den geöffneten Fensterflügeln, hinter denen Spitzengardinen hängen, die ihm so vertraut sind. Wie schon erwähnt, spricht er höchst selten und ungern von sich selbst. Auch von seiner Familie ist in seinen Schriften nur vereinzelt die Rede. Jedoch die Erinnerung, hervorgerufen durch eine optische Täuschung, läßt ihn mitteilsamer werden. Er sieht sich 
wieder als Kind auf dem Hof stehend und zu einem der Fenster hinaufsehend und es scheint ihm fast, als könne er seinen Großvater dort stehen sehen. In typisch Kunertscher Art zerstört er dieses Phantasiegebilde sgigieich wieder:

Und es fehlte nur noch, damit die Illusion phantastische Wahrheit werde, daß mein Großvater dort oben aus dem ersten Stock hinauslehne, als liebenswïrdiger Mittagsspuk, doch starb er weder in dieser noch in seiner wirklichen Wohnung, aus der er, bevor sie in Schutt zerfiel, schon in ein Jenseits deportiert worden war, dessen Pforte, hinter der es keine Hoffnung mehr gab, sich in einer weit entfernten, einer ehemaligen Garnisons- und späteren Ghettostadt befand. (S.106)

Die alten Gebäude mit ihren charakteristischen Zügen bedeuten für diesen Schriftsteller die Seele seiner Stadt. Er fühlt sich mit ihnen so eng verbunden, daß sich ihm ihr Eindruck so eingeprägt hat wie ein „Wasserzeichen". (S.I0?) Fast wie ein Bekenntnis klingt der letzte Satz: "Wollte mir jemand die Haut, die ich zu allen möglichen Märkten trage, abziehen und gegen das Licht halten, er entdeckte weder die üblichen Stempel noch die verbrauchten Symbole, Brandenburger Tor und Funkturm, aber statt dessen etwas wahrhaft Wesentlicheres: ein altes animalisches Haus." (S.10?) In dem kurzen Aufsatz, "Warum Ortsbeschreibungen" (S.163), faßt er die Bedeutung von Ortschaft, Straße und Haus zusammen, indem er auf deren Möglichkeiten des "Formierens und Deformierens" hinweist. Kunert empfindet den Eindruck, den eine Stadt und ihre Häuser auf ihre Bewohner macht, als unauslöschlich. Und da, wie er in dem Prosastück "Häuser an der Spree" sagt, die Steine zu ihm sprechen, fïhlt er auch eine dialektische Verwandtschaft: "Wir und sie, die zwar steinern, doch recht aktiv sind, leben miteinander in einer dialektischen Verknupfung, aus der uns ohne daseinsgefährdenden Schaden nichts loslösen könnte." (S.164) 
In einem Gedicht, "Berliner Nachmittag", spricht Kunert ebenfalls von alten Häusern und deren Inhalt, die von den Wellen des Fortschritts überrollt werden; ein unaufhaltsamer Vorgang, von einigen begrüßt und von anderen beweint:

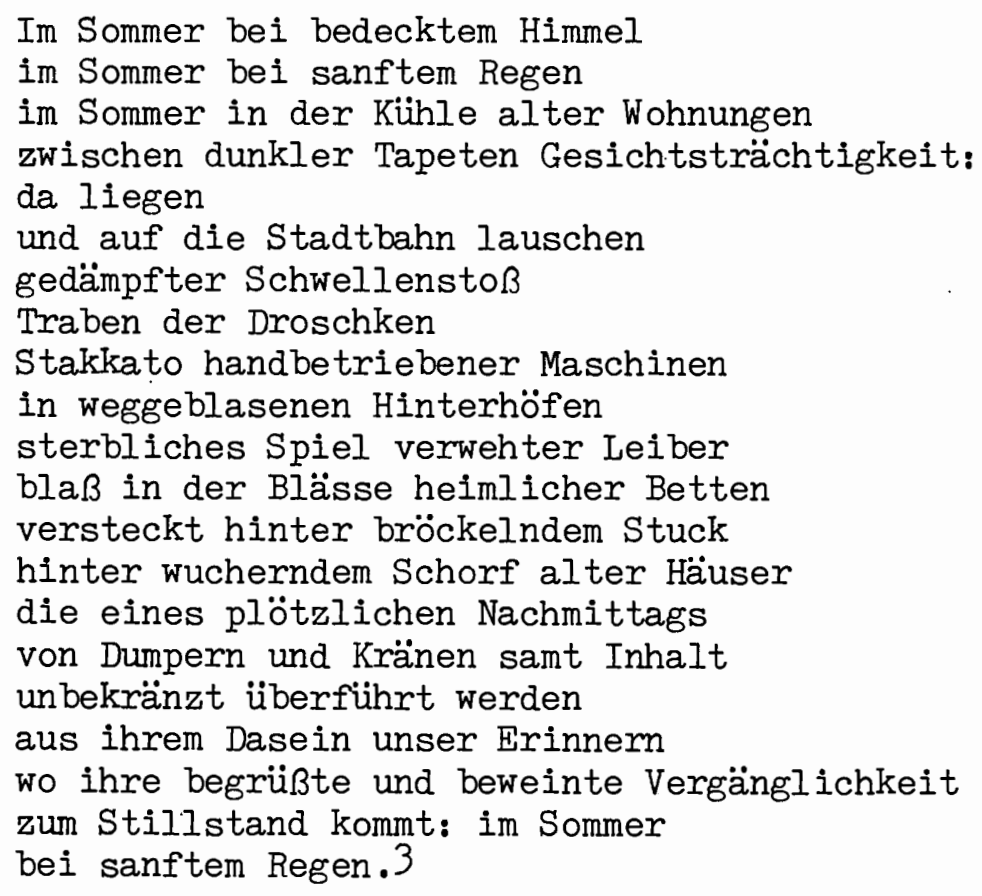

Hier kontrastiert Kunert die Geborgenheit in alten Wohnungen und die Ode weggeblasener Hinterhöfe, beide ein Teil seiner Wirklichkeit. Er selbst bewohnt ein restauriertes Haus aus der Jahrhundertwende, das während des Krieges stark beschädigt wurde. Ständig muß er jedoch mitansehen, wie Gebäude, die für ihn so viel Vergangenheit enthalten, abgerissen werden. In zwei Gedichten aber schreibt er nur von der Stadt, die er liebt und nicht von der Furcht, ihre Essenz zu verlieren. In "A bends gehe ich" zeigt sich ein Gefühl von Gelöstheit und Sorglosigkeit, das für Kunert höchst selten ist: "Abends gehe ich/Leichten Schrittes durch/Meine Stadt."4 Er sieht die Sterme am Himmel flimmern und vergleicht sie mit dem Licht, das aus "verhüllten Fensterm an schwarzer Häuserburg" scheint. 
Er läuft mit federnden Schritten einem Ziel zu.

Im gleichen Band enthalten ist "Morgen kommt", ein Gedicht, das eine ähnliche Gelöstheit ausdrückt. Die Liebe zu seiner stadt wird hier unterstrichen, da sie einer Liebe zu einem Menschen gegenüber gestellt wird. In diesen Zeilen hält Kunert einen Augenblick fest, in dem es für ihn keinen beunruhigenden Gedanken zu geben scheint:

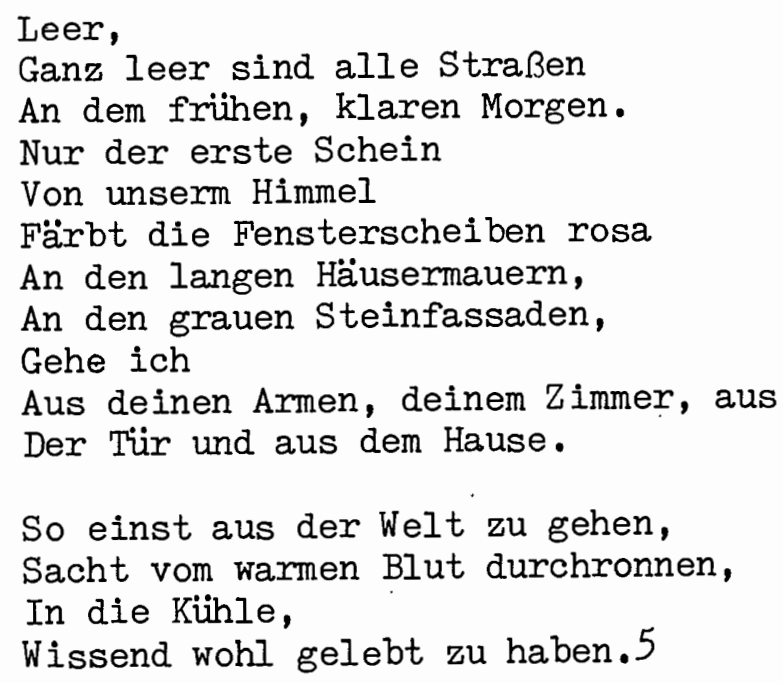




\section{PARADOXIE ALS PRINZIP}

In Warum schreiben bespricht Kunert Paradoxie, ein Prinzip, das, wie er sagt, "der Lyrik eingeboren ist".1 Um dieses Prinzip zu verdeutlichen, führt er zwei Gedichte an: "Ikarus 64" und "Notizen in Kreide", die sich in ihrer Form kaum voneinander unterscheiden. Beide Gedichte bestehen aus freien Rhythmen ohne Reim, in beiden findet sich Alliteration, Unabgeschlossenheit und der Kontrast des Möglichen und des Unmöglichen. Das lyrische Ich erscheint als Verbindung individueller und gesellschaftlicher Komponenten:

Aus diesen Komponenten entsteht der Spannungszustand des Gedichts; ein Spannungszustand, der aus dem scheinbar Widersinnigen, Unzuvereinbarenden herrührt: aus der Paradoxie. Paradoxie ist aber nichts weiter als die Momentaufnahme, als der Schnappschuß eines dialektischen Vorganges. Er ereignet sich im $\mathrm{Ge}-$ dicht im Iyrischen Ich zwischen dessen subjektivem und objektivem Teil. (S.278)

In "Ikarus 64" beweist Kunert in den ersten zwei Strophen die Unmöglichkeit des Fliegens, setzt aber in der dritten Strophe voraus, daß dennoch ein immer wieder neuer Anlauf gemacht werden muß, um das Unmögliche zu erreichen:

Dennoch breite die Arme aus und nimm einen Anlauf für das Unmögliche. Nimm einen langen Anlauf damit du hinfliegst $\mathrm{zu}$ deinem Himmel daran alle Sterne verlöschen. Denn Tag wird. Ein Horizont zeigt sich immer. Nimm einen Anlauf. (S.276) 
Diese Aufforderung enthält aber in dem Wort "hinfliegst" ein Paradoxon, das auf die Möglichkeit des Mißlingens hinweist. Jedoch zeigt sich immer ein Horizont und immer eine Möglichkeit, einen neuen Anlauf zu nehmen. In den letzten beiden Zeilen kommt die Unabgeschlossenheit des Gedichts zum Ausdruck, für Kunert ein wichtiges Element in seiner Lyrik: "... Unabgeschlossenheit, was ebenfalls zur Spannung wie zum Realismus des Gedichts gehört." (S.279) Wenn in "Ikarus 64" die Unabgeschlossenheit als positiv gesehen werden kann, so zeigt sich in "Notizen in Kreide" das Unabgeschlossene der letzten Strophe als negativ:

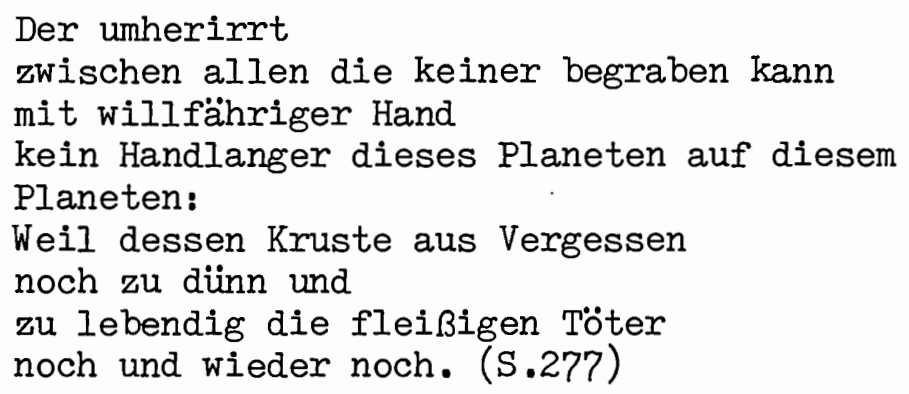

Der Widersinn liegt in der Unabgeschlossenheit der Vergangenheit, die zur Gegenwart wird, da die Schuldigen noch am Leben sind. "Durch die Existenz der Mörder sind die Ermordeten noch vorhanden - im Bewußtsein der Lebenden. Das ist das Paradoxon von 'Notizen in Kreide'." (S.279) Dieses antifaschistische Gedicht bezieht sich ausschließlich auf "das kontinuierliche Fortkommen der Schuldträger im anderen deutschen Teil." (S.280) Kunert schließt seinen Staat von dieser Anklage aus, da er, wie er sagt, aus einer historischen Zäsur erwachsen sei und daher die Erbschaft mörderischer deutscher Misere nicht angetreten habe. (S.279-80) Dennoch fühlt er sich verpflichtet, diese Anklage zu formulieren, denn sie gehört für ihn zum Realismus der Gegenwart, den er als ein erstrebenswertes Element 
der Lyrik sieht:

Realismus in der Gegenwart, der erstrebenswert ist, mir zumindest, erscheint als Haltung, die die großen politischen ökonomischen gesellschaftlichen Zusammenhänge nicht als unwürdige unreine unpoetische Plattheiten ansieht, sondern begriffen hat, wie sehr das Individuum an ihnen teilnimmt; mehr: daß eigentlich sie, die Umstände, im wahrhaftigsten und tiefen Sinn des Wortes den Menschen ausmachen. Diesem Realismus nützlich ist solche Paradoxie, die dialektische Momente sichtbar werden läßt. (S.280)

Kunert will damit jedoch nicht sagen, daß Paradoxie Realismus erzeugt. Das Paradoxon soll nur das unterstreichen, was schon in der Wirklichkeit unvereinbare Polarisierung zeigt, wie, beispielsweise, das menschliche Unvermögen des Fliegens und der Versuch, es dennoch möglich zu machen; oder die Gegenwart der Toten, die durch die Existenz ihrer Mörder noch vorhanden sind.

Neben der inneren Paradoxie des Gedichts, sieht Kunert auch eine äußere. Das Verhältnis zwischen Gedicht und Leser, der von Massenmedien und Trivialliteratur überschwemmt wird, bildet dieses Paradoxon. Kunert hält es für unwahrscheinlich, daß der Leser, der von diesen Einflüssen überreizt ist, noch aufnahmefähig für den subtileren Reiz der Lyrik sein kann:

In einer Gegenwart wie der unsrigen, die dem Massenkonsum von Kunst förderlich ist und die daher Kunst fördert, die leicht konsumiert werden kann und die in ihrer Konsumierbarkeit immer mehr der Passivität des Konsumenten entgegenkommt, muß die Lage der Lyrik, die, falls sie sich nicht aufgeben will, der rezeptiven Mïhe des Lesers bedarf, paradox sein und ständig paradoxer werden. Die Lyrik wird immer schwerer aufnehmbar durch das, was sie erst zur Lyrik erhebt. (S.283)

Ein weiteres Paradoxon entsteht dadurch, daß Kunert hofft, daß gerade durch die Suggestibilität der Massenmedien eine Abstumpfung gegen ihre 
eigene Wirkung eintritt und somit das Verlangen nach geistiger und emotionaler Aktivität gesteigert wird. (S.284) Wenn dieser Vorgang sich so entwickelt, dann hat der engagierte Dichter eine Möglichkeit, diese Chance zu nutzen und den Leser auf seine Weise zu beeinflussen, die zur "Entgröberung", "Sublimierung" und sogar zur „Humanisierung" führen könnte.

Durch die Wechselbeziehung von Abstumpfung durch Massenmedien und dem Verlangen nach intellektueller Aktivität kann dem Leser nicht nur die Lyrik, sondern auch das lyrische Ich näher treten. Kunert beschreibt den Einfluß des lyrischen Ich auf den rezeptiven Leser: „Das spannungsträchtige lyrische Ich und das Leser-Ich werden während des Lesens identisch und gleichzeitig nicht identisch; das eine verfremdet das andere und deckt es doch gleichzeitig. Das Gedicht färbt die Psyche des Lesers, er wiederum färbt nach seinem Ebenbild das Gedicht." (S.285)

In der Kurzprosasammlung Tagträume in Berlin und andernorts (1972) zeigt Kunert, daß Paradoxie nicht nur in seiner Lyrik erscheint. In dem kurzen Stück "Ernte" beschreibt er mit der für ihn oft typischen Ironie das Paradoxon von Dummeit im Uberfluß und dem Mangel von Dummheit. Er beginnt mit dem Sprichwort: "Die Dummheit wächst an den Bäumen."2 Er läßt die Dummheit als ein Naturprodukt erscheinen, das wegen seines Uberflusses unbeachtet bleibt. Da es jedoch Gärtner gibt, die Dummheit ernten und zum Verkauf anbieten, zeigen sich sofort eifrige Käufer, die dem Sonderangebot "Heute ganz frische Dummeit zu verkaufen!" nicht widerstehen können. (S.83) Die Leute geben ihr letztes Geld her, um sich pfund- und körbeweise Dummeit zu erstehen. Die letzten fünf Zeilen sind ein Musterbeispiel für Kunerts Paradoxie: Arm, sorgfältig gehütet, denn wer weiß, ob sie nicht eines Tages 
durch Mißermte knapp wird, was zur unabsehbaren Folge hätte, daß statt dessen jeder zur Vermunft greifen müßte, die noch keinem bekommen ist. 3

Aus der gleichen Sammlung stammt ein weiteres Beispiel der Paradoxie mit dem Titel "Hinausschauen". Die zugrundeliegenden Gedanken sind hier die polarisierten Elemente von Schein und Wirklichkeit, von nach außen hin bewahrter menschlicher Sicherheit und innerlicher Unsicherheit. Im ersten Abschnitt zieht Kunert den Leser in seinen Gesichtskreis ein, indem er voraussetzt, daß jeder gern aus seinem Fenster die voribergehenden Passanten beobachtet und allerlei Vermutungen über sie aus dieser überlegenen Warte anstellt. So befaßt Kunert sich mit den weiblichen Spaziergängern, die im Sommer „äußerst bewegliches Fleisch zur Schau tragen, später in der Kälte geheimnisvolle Mäntel, darunter meist hitzig-heißes Leben vermutet wird und meist irrtülich."4 Er beschreibt eine Reihe von alltäglichen Erscheinungen: Autos, Pferde, Polizisten, Panzer und Milllwagen. Bis zu diesem Punkt wird dem Leser ein Bild belangloser Alltäglichkeiten übermittelt, das durch die Worte "bequem", "gemütlich" und "anheimelnd" unterstrichen wird. Der paradoxe Wendepunkt entsteht, indem sich der Blick auf den Beobachter richtet, der sich nicht bewußt ist, was hinter seinem Rïcken geschieht. Während er nichtsahnend weiterhin aus dem Fenster sieht, wird hinter ihm das ganze Haus abgerissen:

\footnotetext{
..., so daß man, noch eben über einen Spaziergänger gebeugt, plötzlich ohne Hintergrund ist, ohne festes Dach und ohne Boden unter den Fỉßen, eigentlich bereits in der Luft hängt und nur fïr die draußen auf der Straße unverändert anheimelnd aus dem Fenster sieht: Wie gefährlich das ist, ahnt keiner, der vorbeigeht. (S.44)
}

Zwischenmenschliche Beziehungen bestehen nicht und die beiderseitige Anonymität trägt dazu bei, den Schein der Sicherheit zu wahren. Der Beobach- 
ter hat das Fundament unter seinen Fïßen verloren, doch das ahnt keiner, der vorbeigeht. In einem Aufsatz, "Versuch über meine Prosa", schreibt Kunert: "Unsere sogenannten 'zwischenmenschlichen' Beziehungen sind seit dem ersten Drittel unseres Jahrhunderts durch zwei Aspekte bestimmt; Anonymität und Verdinglichung." 5 Er führt den Gedanken zu Ende: „Wir begegnen einander nur funktional, emotional unbeteiligt, als zwei Gegenstände, zugunsten einer überlagernden Funktionsebene kurzfristig miteinander beschäftigt."6 Diese Anonymität und Verdinglichung sind schon Hauptthemen in Brechts Großstadtlyrik aus den zwanziger Jahren. Obwohl sie auch eine Rolle in Kunerts Stadtbeschreibungen spielen, so wurde im vierten Kapitel jedoch gezeigt, daß er sich nicht nur kritisch, sondern auch mit merkbarer Zuneigung mit seiner Stadt Berlin befaßt. 
DAS LYRISCHE ICH

Während in der Mehrzahl der Gedichte und auch in der Prosa Kunerts Iyrisches Ich Distanz bewahrt und den Standpunkt des Beobachters einnimmt, so gibt es doch Bereiche, von denen er sich nicht distanzieren kann. In diese Kategorie fallen die drei schon fruher besprochenen Gedichte „Wie ich ein Fisch wurde", "Filr mehr als mich" und "Neues vom Amt III". Sein Iyrisches Ich tritt hier in den Vordergrund, ausgelöst durch gesellschaftIiche Gegebenheiten. Meistens läßt Kunert den Leser nur erraten, was für ein psychisches Ich hinter seinen Worten verborgen ist. In seinem "Selbstporträt im Gegenlicht" (1972) gibt er jedoch einen Einblick, der eine Erklärung dafür sein könnte, warum er so selten sein lyrisches Ich sprechen läßt. Er erscheint sich selbst fremd und unbekannt und gesteht, daß er wenig vom Kern seines Wesens wisse und nur von seinen äußeren Lebensumständen Kenntnis habe.1 Er liberlegt sogar, ob er denn uberhaupt selbständig lebe:

...ob er nicht einfach eine sichtbar gewordene Metamorphose dieses liniierten Papiers ist, da alle Wege seines Tagesablaufs, seines Lebenslaufes zu den Papierblättern hinführen, deren Menge jeweils nach der Begegnung mit Kunert abnimmt: Verwandlung von DIN A 4-Bogen in so etwas Ähnliches wie einen Menschen durch die Katalyse des Schreibens auf eben diese Bogen. Der Vorgang des Schreibens jedoch verwandelt nicht allein Papier in einen Kunert, es verwandelt auch Kunert in etwas, das zu begreifen, zu erklären, zu umschreiben und damit exakter zu benennen er immer aufs neue Papier mit wörtern bedeckt.2 
Wesens, denn er beschreibt genau, was für ihn die Essenz des Lebens bildet, die ihn überleben läßt und ihn zum Individualisten macht:

Es ist ein Zustand, in dem das beängstigende, zermürbende, verzweiflungsschaffende Abschnurren der Zeit aufzuhören scheint; in dem sie beinahe stillsteht: am Rande des unsäglichen Abgrundes, in den zu stiirzen das Schreiben verhindert. Schreiben ist Rettung vorm Tode, solange es anhält. Das ist der Augenblick der Wahrheit, da sich das Individuum seiner Individualität begibt und sich aufs innigste mit dem unsterblichen Ich menschlicher Allgemeinheit verquickt, das wiederum sonst $\mathrm{zu}$ Gesichtslosigkeit und Abwesenheit verdammt, selber das am Tisch hockende, übers Papier geneigte, haarloser werdende Individuum braucht, um sich zu manifestieren und sichtbar zu sein.3

Die Gegenpole des Sichnichtkennens und der Selbsterkenntnis sind fundamentale menschliche Probleme, deren Kunert sich deutlich bewußt ist. Aus diesem Grunde ist vielleicht der Standpunkt des Beobachters die Warte, die Kunert vorzieht. Eins der Themen, das er öfters behandelt, läßt sein lyrisches Ich jedoch Klar - wenn auch ein wenig skeptisch - in den Vordergrund treten, nämlich das Element der Hoffnung. Zwei Gedichte, die dem Band Was uns manchmal bewegt (1963) entstammen, seien als Beispiel erwähnt:

\author{
LEG DEN KOPF INS GENICK \\ Wenn die klare Nacht kam. \\ Groß ist das Angebot heute \\ An Sternen, Planeten, Sonnen und \\ Welten. \\ Dabei ist auch eine \\ Fïr dich und mich. \\ Die gleiche. 4
}

Vielleicht aus seiner eigenen politischen Lebenssituation heraus entsteht die Frage, ob die ideale Welt Elemente enthalten könne, die für alle Menschen gleich positiv wären. In diesem Gedanken liegt Kunerts Skepsis und doch hat er Hoffnung auf eine Welt, die sich aus positiveren Elementen zu- 
sammensetzt als die der Vergangenheit und die der Gegenwart, eine Welt also, die sich nicht nur aus Bürgern einzelner Staaten zusammensetzt, sondern eine Welt bevölkert von Weltbürgern. Fïr einen Weltbürger hält er sich selbst, wie er in einem Gespräch mit Dieter E. Zimmer erklärt. Auf die Frage, ob er sich gern einen "DDR-Autor" nennen ließe, antwortet Kusert:

Ich bin nicht empfindlich, finde aber, daß eine derartige Bezeichnung nichts sagt. Sollte sie gar einschränkend gemeint sein, trifft sie auf mich bestimmt nicht $z u$. Ich halte mich für einen kosmopolitischen, internationalen, meinetwegen "internationalistischen", gar weltbiirgerlichen Autor, der seinen Wohnsitz in der DDR hat und dort auch die Konflikte, die sein Material sind, frei Haus erhält.5

In dem kurzen Gedicht "Auf der Schwelle des Hauses" erfährt sein lyrisches Ich ein physisches, fast erotisches Gefül. Er sitzt in den Dïnen, spürt die Wärme der Sonne, hört nichts als die ewige Brandung der Wellen und scheint durch die Wahmehmung dieser elementaren Kräfte mit ihnen verbunden, durch sie geborgen zu sein.
Auf der Schwelle des Hauses
In den Diinen sitzen. Nichts sehen
Als Sonne. Nichts fühlen als
Wärme. Nichts hören
Als Brandung. Zwischen zwei
Herzschlägen glauben: Nun
Ist Frieden.6

Das Gefühl der Ruhe und Geborgenheit ist in Kunerts Gedichten und Prosa selten zu finden. In diesem Gedicht aber drückt er ein Gefühl aus, das ihn auf einen tiefen, inneren Frieden hoffen läßt. Er sagt nicht: "Zwischen zwei Herzschlägen wissen", sondern er sagt: "Zwischen zwei Herzschlägen glauben". Das Wort "glauben" sollte hier nicht als "sich einbilden" oder "sich glauben machen" verstanden werden, sondern eher als ein 
Synonym des Wortes "hoffen".

Kunerts lyrisches Ich erscheint auch in "Hoffnungsgedicht" (1975), das er im ab/ab Reim hält. Hier zeigt er die Schatten- und Sonnenseiten des Lebens und fordert dazu auf, sich ganz den Sonnenseiten hinzuwenden, sich ganz den Elementarkräften der Natur anzuvertrauen, die den einzigen, wahren Sinn des Lebens bilden. In der letzten Strophe drückt er einen Wunsch aus,

daß alles ein Spiel sei, einmal nur zu spielen, verzichten auf Blut, auf Verlust und Gewinn, einmal auf Wonne, auf Wohlsein nur zielen, dem Wasser gehorchen, dem Licht, dem einzigen Sinn.?

Das Gefïhl des sicheren Eingegliedertseins in den Bereich der Natur scheint Kunert dazu zu veranlassen, sein lyrisches Ich in den Vordergrund treten zu lassen. Ein ähnliches Gefühl ist zu bemerken, wenn er Gedichte über den Berliner Vorort schreibt, in dem er lebt. Wiederum scheint das Ich von einer Geborgenheit auszugehen und sich dadurch deutlicher zu zeigen. Umgeben von vertrauten Gerïchen, Geräuschen und Nachbarn erlebt er den Bucher "Vorortabend" (1974). Eine feierliche, fast ehrfurchtsvolle Stimmung verleiht er dem Gedicht, indem er den biblischen Schöpfungsakt be jahend nachvollzieht:

Hier geht die Luft geruhsam umher. Hier brennt eine Gaslaterne und da auch. Hier riecht es nach Flieder und Rauch einer verlorenen Lokomotive. Die Geräusche gelangen weiter

als am Tage, beflügelt von schwarzen Schwingen. Hinter der Hecke jedes gesprochene Wort ist so, wie es am Anfang war: ein Beginn. So kommen die Sprechenden erst später zu ihrer Sprache hinzu, werden Nachbarn 
aus Fremden, umgeben sich

mit ihren Gärten, mit holprigen Straßen,

mit Eisenbahngleisen, mit Universum:

Es werde Vorort.

Es werde Abend.

Es werde Schweigen.

Fïr heute Nacht nehme ich

die Schöpfung zurïck. 8

Abschließend sei hier ein Gedanke Kunerts zum lyrischen Ich angefïhrt: "Im Ich des Gedichts exscheint - und darum zur Befreiung gerufen - das unverkrüppelte, vollkommene, wenn auch ewig unvollkommene Individuum ein Windhauch aus Utopia." 9 
DAS „BEWUßTSEIN” DES GEDICHTS

Die Vielfältigkeit von Kunerts Form scheint unbeschränkt zu sein. Er experimentiert mit den verschiedensten Genren: Lehr- und Warngedichte, Balladen, Epigramme, Porträts, "Zeitraffer"-Poesie, Naturlyrik, Lieder und Kurzprosa sind für ihn Formmöglichkeiten. Da Kunert sich meist mit Sachverhalten befaßt, die das Interesse der Allgemeinheit beanspruchen, nimmt er den Standpunkt des Beobachters ein. Er fühlt sich zur Analyse verpflichtet und bewahrt "kalte" Distanz dem Gegenstand gegenüber. Daher ist seine Sprache oft gestisch, eine "anzeigende", "entdeckende" Sprache. Einige kritische Leser haben sie als belehrend und schulmeisterlich empfunden. Es muß jedoch anerkannt werden, daß er sich selbst nie von diesen "Belehrungen" ausschließt. Eine korrektive Beziehung des Autors zu sich selbst ist immer ersichtlich. In seiner Sprache verwendet Kunert hauptsächlich den Subjektsatz und den Bedingungssatz, Sätze also, die identifizieren und polarisieren. Wenn er These und Antithese aufstellt, gebraucht er eine Parallel- und Wiederaufnahmetechnik. Kunerts Sprache kann ausgesprochen lapidar und lakonisch sein und gerade dadurch zwingend überreden. Seine Lyrik besteht hauptsächlich aus freien Rhythmen und unregelmäßigem Bau der Verse und Strophen, deren Dichte und Länge unterschiedlich sind. Diese Regel- und Reimlosigkeit unterstreicht die Distanzierung vom Gegenstand, die Kunert als Beobachter einnimmt. Er ist jedoch auch in der Iage, im Bereich der traditionellen Metren und Reime zu arbeiten. In diesen gebundenen Gedichten erlaubt er sich Identifikation und 
äußert Gefïhl und Empfindung. Sein Ich kommt stärker zum Ausdruck, besonders wenn er von. Dingen spricht, die ihn unmittelbar betreffen, wie zum Beispiel von Liebe, Natur, Freundschaft und Städten.

Die Schreibweise, die Kunert bevorzugt, ist die des Gedichts. Das Gedicht ist für ihn eine künstlerische Herausforderung, eine Form, die einen höheren Grad der Bearbeitung verlangt als die erzählende Prosa.I Das Empfinden des Schriftstellers kann in der Lyrik durch Metren ausgedrückt werden, die seiner augenblicklichen Stimmung entsprechen. Alliterationen, Synonyme, Homonyme, Assoziationsmöglichkeiten und metaphorische Analogien bieten Ausdrucksformen, die ein Gedicht vervollkommnen können. "Bevorzugt man die dem ästhetischen Empfinden entgegenkommendere, gelungenere Formulierung, kann es geschehen, daß sich, wenn auch um weniges, das Bild verschiebt und damit selbstverständlich auch die Bedeutung." (S.257) Dieser Gedanke Kunerts sollte nicht nur auf rein kïnstlerischer Ebene verstanden werden, sondern auch auf einer, die in seiner politischen Situation relevant ist. Die Möglichkeiten des Gedichts, die den scheinbar offensichtlichen Inhalt vertiefen, erweitern oder gänzlich verändern können, bilden das in einer politischen Diktatur dichterisch lebensnotwendige Element. Obwohl Kunerts Themenwahl durchaus nicht in neue Sphären eindringt, so verleiht er seinen Gedichten jedoch immer einen neuen Aspekt und eine neue Betrachtungsweise, die sie zeitgenössisch und relevant werden lassen. Die Problematik seiner Zeit und die des menschlichen Daseins im Besonderen, veranschaulicht der Dichter aus eigener Sicht. $\mathrm{Zu}$ einer Transformation der Wirklichkeitsebene im Gedicht gehört jedoch eine kïnstlerische Unabhängigkeit, die Kunert so formuliert: "Seine Freiheit, die künstlerische Freiheit, ist niemals der politischen gleichzusetzen; es ist dies der eingangs erwähnte Vollzug des Schreibens; in welchem er 
seine Freiheit, begrenzt von keinem anderen Gesetz als dem der literarischen Gattung, finden muß." (S.259) Er versucht zu diesem Zweck auch, die Sprache von ihrem alltäglichen Nutz- und Informationswert zu befreien und sie durch dichterischen Eigensinn zu prägen. Diese befreite Sprache wird "das Mittel zur individuellen Metamorphose des Dichters." (S.260) Die Selbstverwirklichung ist für Kunert der künstlerische Höhepunkt, den er aber als Paradoxon empfindet:

... in einer Welt wachsender Zweckdienerschaft gelungene Selbstverwirklichung, ein Sieg, der jedoch die Niederlage enthält: nämlich nur Selbstverwirklichung im Raum der Abstraktion - darin besteht neben dem Glücksgefühl der Dichter ihr scheinbar grundloses Leiden: es resultiert aus der Gewißheit, fuir die Verwandlung ihres Blutes in Worte eben um dieses Maß an Lebensfiulle und Leben betrogen worden zu sein. Zwar haben sie sich selber mittels der Sprache erhoben und intensiviert, im selben Augenblick aber veräußerlicht und fortgegeben. So wird ein Gedicht über Selbsterkenntnis möglich, sogar Selbsterkenntnis selber, deren Nutzen fragwirdig ist, denn ihr erkannter Gegenstand ist ein unaufhebbarer Widerspruch. (S.260)

Obwohl Kunert dieses Paradoxon erkennt und akzeptiert, hindert es ihn nicht daran, in seinen Gedichten immer wieder eine sprachliche Vervollkommung anzustreben. In dem kurzen Aufsatz "Zeitgenossenschaft des Gedichts", der das Nachwort zu dem Gedichtband Offener Ausgang bildet, verdeutlicht er die vielschichtigen Sprachmöglichkeiten. Er betont die "Unselbstverständlichkeit der Sprache", durch die ein Gedicht an Bedeutungsfülle, Farbe, Schönheit und Intensität gewinnen kann.2 Durch diese Unselbstverständlichkeit der Sprache, die in Kunerts Gedichten offenbar ist, wird die Lyrik zu einem autonomen Bewußtseinsgebilde. Jedoch liegt diesem Bewußtseinsgebilde das individuelle Weltverständnis des Schriftstellers zugrunde: "Meine Gedichte sind meine Gedichte: Entsprechungen meines Selbst, eines Selbst, welches nachdrücklich zeit- und gesellschaftsgeprägt 
worden ist." 3

Ein anderer Widersinn liegt für Kunert im Gedichteschreiben überhaupt. In seinem Aufsatz "Warum schreiben" erklärt er: "Das Motiv ist ganz simpel: um zu leben." 4 Allerdings meint er damit nicht nur "leben" im Sinne von Lebensunterhalt, sondern auch das psychische Sich-am-LebenErhalten. Schreiben ist für diesen Schriftsteller ein dialektischer Regenerationsproze $\beta$, bei dem er Text wird und bei dem er zugleich verliert und gewinnt.5 Dieser Gedanke tritt in "Gedicht zum Gedicht" deutlich hervor:

\author{
Mehr als ein Gedicht \\ ist beispiel sweise: Kein Gedicht, \\ denn das Nichtgedicht lebt \\ als sanfte Lauheit der Inspiration: \\ Umwel tgefiihl \\ des Tropfens im Wasser. \\ Der Leib fühlt sich geborgen. \\ Das Herz fiuhlt nichts. \\ Die Waage ist ausgeglichen. \\ Das Lot hängt still. \\ Gedicht ist Zustand, \\ den das Gedicht zerstört, \\ indem es \\ aus sich selber hervortritt. 6
}

Trotz dieses Paradoxons des Gedichts, das sich zerstört indem es aus Inspiration zum Gedicht wird, fühlt Kunert den für inn lebensnotwendigen Drang zum Schreiben. Die Hoffnung, etwas Beständiges, etwas Permanentes zu vollbringen, kann als ein Grund dafür angeführt werden. „Schreiben: damit sich ereignet, was jeder insgeheị wünscht: da $\beta$ der Moment einen Moment lang Dauer behält und immer wieder erweckt werden kann."?

In einem Gedicht mit dem Titel "So soll es sein" behandelt er ebenfalls das Thema des Widersinns des Gedichtes. Schon der Titel weist darauf hin, daß der Dichter den Widersinn akzeptiert: 


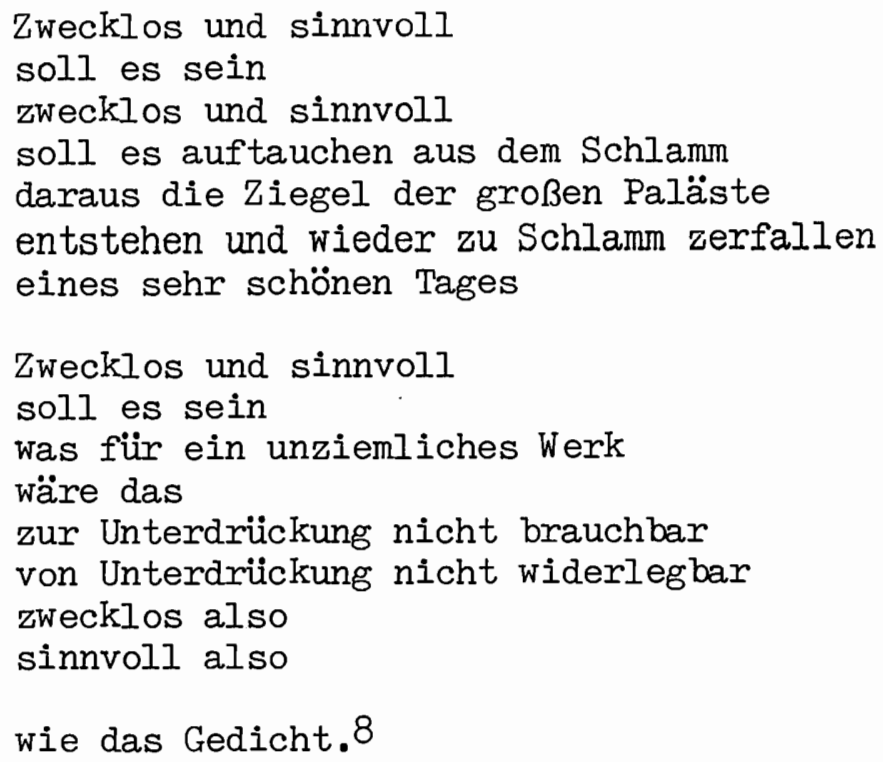

Die mehrmalige Wiederholung der Worte "Zwecklos und sinnvoll" unterstreicht den Prozeß des Gedichteschreibens, indem das Gedicht sich selbst zerstört, wenn es aus Inspiration zu Realität wird. Dennoch hat es eine Funktion erfüllt, ja sogar einen Sieg davongetragen. Durch seine interne Sprache ist das Gedicht „zur Unterdrückung nicht brauchbar" und "von Unterdrückung nicht widerlegbar". In diesen beiden Zeilen kann ein weiterer Grund dafür gesehen werden, warum Kunert die Lyrik als Form bevorzugt. Wie Brecht glaubt er an die Kraft der Kritik, die zu Veränderungen führen soll. Da offene Kritik aber in einer Diktatur unerlaubt ist, greift Kunert vielfach auf die Sprachmöglichkeiten des Gedichtes zurïck, die ihm größere Ausdrucksfreiheit zu geben scheinen. Es ist gerade Kritik an dem System, das kritische Außerungen nicht zuläßt, die immer wieder das Thema in seiner Lyrik bildet. Was geschehen kann, wenn der Kritik die Stimme genommen wird, deutet Kunert in "Die Schreie der Fledermäuse" an. Er beschreibt den Flug der Fledermäuse, die laut schreiend durch die Dämmerung fliegen. Sie orientieren sich an verschiedenen Schallkulissen, die ihnen mitteilen, wo sich Hindernisse erheben oder wo ein freier Weg zu finden 
Ihre Schreie sind jedoch nur von ihresgleichen zu vernehmen. "Nimmt man ihnen die Stimme, finden sie keinen Weg mehr; überall anstoßend und gegen Wände fahrend, fallen sie tot zu Boden. Ohne sie nimmt, was sonst sie vertilgen, überhand und großen Aufschwung: das Ungeziefer."9 Hier scheint es klar, an wen Kunert die Aufforderung zur Kritik richtet. Es ist der gleichgesinnte Leser, der sich von den Verhältnissen seiner politischen Gegenwart eingeschränkt und unterdrückt fühlt.

Kunerts Lyrik enthält meist eine Mischung von Resignation und vorsichtiger Hoffnung. In dem Gedicht "Unterwegs nach Utopia I" tritt das Gefïhl der Resignation stark hervor:

\author{
Vögel: fliegende Tiere \\ ikarische Züge \\ mit zerfetztem Gefieder \\ gebrochenen Schwingen \\ überhaupt augenlos \\ ein blutiges panisches \\ Geflatter \\ nach Maßgabe der Ornithologen \\ unterwegs nach Utopia \\ wo keiner lebend hingelangt \\ wo nur Sehnsucht \\ überwintert. 10
}

Kunert gebraucht in dieser ersten Strophe eine Analogie - Vögel, fliegende Tiere, die in blindem, panischem Flug einem unbekannten Ziel entgegenflattern - ein vergebener Versuch, der der menschlichen Sehnsucht nach der idealen Welt entspricht. Die letzte Strophe löst das Gefühl der Resignation auf und drïckt statt dessen eine tiefe Hoffnung aus. Diese Hoffnung sieht Kunert in der Beständigleit des Gedichtes:

Das Gedicht bloß gewahrt was hinter den Horizonten verschwindet etwas wie wahres Lieben und Sterben die zwei Flügel des Lebens 
bewegt von letzter Angst

in einer vollkommenen

Endgültigkeit. (S.293)

Dieser Dichter, der alles in Frage stellt, schließt auch das Absolute des Gedichtes nicht aus. In einem Aufsatz schreibt er: "Was nutzen Gedichte schon? Was reflektieren sie denn außer dem instabilen Bewußtsein ihrer Produzenten?"II Seine eigene literarische Existenz erscheint ihm fragwürdig, wenn er sie den Realitäten der Vergangenheit und der Gegenwart gegenüberstellt. Die Frage nach dem Nutzwert der Lyrik läßt einen Schuldkomplex entstehen, den er als das Resultat von "selbst erfüllender Prophezeiung" sieht. "Uberzeugt von der eigenen Uberflüssigkeit, wird man wirklich überflüssig." (S.263) Dem Leser dieses Aufsatzes wird allerdings sogleich klar, daß Kunert nur - wie üblich - Prüfung gesellschaftlicher Prämissen und individueller Positionen fordert und daß er durchaus keiner selbst erfüllenden Prophezeiung unterliegt. Er erklärt den Gedanken des Gebrauchswertes des Gedichts mit den oft zitierten Zeilen: „Brauchen die Hungernden Gedichte? Sie brauchen Nahrung, soviel ist sicher. Aber sie brauchen genauso das Bewußtsein ihres ihnen vorenthaltenen Menschentums und damit die Gewißheit, daß ihnen mehr fehlt als die Befriedigung ihrer Bedürfnisse, gleichgültig, wie immer diese Bedürfnisse stègen werden und wie deren Befriedigung." (S.267) Damit ist der unleugbare Sinn des Gedichtes wieder hergestellt. Die Kraft des Gedichtes liegt für Kunert in der Subjektivität, die auf der individuellen Erfahrung des Lyxikers basiert. Den Sinn des Gedichtes sieht er in dem angestrebten Moment, in dem andere Individuen sich damit identifizieren. Diese Identifikation geschieht, "wenn die Empirie exemplarisch wird oder zumindest durch sprachlichen Ausdruck nachvollziehbar." (S.265) Der Lesende soll in der Gedichtaufnahme seiner selbst als Symptom bewußt werden, indem das Gedicht 
sein indifferentes Selbstgefühl artikuliert. "Form und Formulierung des Gedichts formen und formulieren den diffusen mentalen Inhalt des Lesers, der auf diese Weise, durch das Bewußtsein des Gedichts, zum Selbstbewußtsein, durch Selbstbewußtsein zum Weltbewußtsein gelangt." (S.265) Kunert will damit jedoch nicht sagen, daß das Bewußtsein des Gedichts in erster Linie das. gesellschaftlich herrschende einer Epoche sein soll. Im Gegenteil, wäre es restlos vom Geist seiner Zeit bestimmt, so würde es - laut Kunert - zusammen mit seinem Zeitgeist erlöschen. Es sind Gedichte, die mehr als bloßen Zeitgeist enthalten, die ihre Epoche überdauern. Als Beispiel führt er zwei Namen an:

Villon und Hofmannswaldau. Ihre Gedichte bewegen uns noch immer; nicht, weil sich in Hunderten von Jahren so wenig geändert hätte, sondern weil, trotz großer Umwälzungen, in diesen Gedichten ein Bewußtsein evident ist, eine Wahrheit, die der Kondition des geschichtlichen Menschen eigen ist. (S.266)

Die im Gedicht reflektierte Realität ist für Kunert anders als in jeder anderen Literaturgattung. Er bezeichnet das Gedicht als „älteste Kunst, aus Magie stammend, aus Metaphysik und Irrationalismus." (S.268) Er sieht es also als unzeitgemäßes Relikt in einem technologischen Zeitalter. Was für eine Realität reflektiert demnach das Gedicht? Für diesen Schriftsteller lebt in jedem Gedicht eine Ahnung von der Verkehrtheit der Welt, mit der er sich ständig auseinanderzusetzen versucht und die sich in vielen seiner Gedichte widerspiegelt. Aus ontologischer Warte beobachtet das lyrische Bewußtsein, "das noch in den winzigsten Entwurf eine Ahnung des ganzen Seins einbringen möchte." (S.268) Dieser Schriftsteller reflektiert die Realität; wie sie ihn betrifft und wie er sie interpretiert. Diese individuelle Aussage ist für ihn lebensnotwendig, so wie

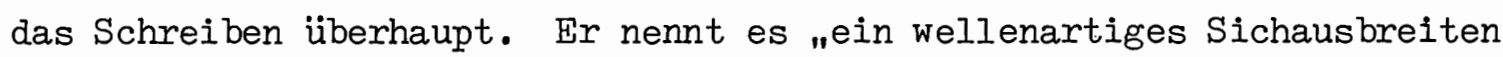


nach allen Seiten, das Grenzen ignoriert und immer mehr und immer Unbekannteres einbezieht und erhellt." (S.205) Die Deutung des Bekannten und die Erhellung des Unbekannten werden von der Wirklichkeitsebene in die Dialektik seiner Lyrik übertragen. Das Schreiben selbst bedeutet Wirklichkeit für Kunert, denn er sieht es als einen Regenerationsprozeß, in lem er sich geistig immer wieder erneuert und der ihn die Unbeständigkeit seiner Welt ertragen läßt:

Schreiben: weil Schreiben nichts Endgültiges konstituiert, sonderm nur Impulse gibt; weil es ein unaufhörlicher Anfang ist, ein immer neues erstes Mal, wie Beischlaf oder Schmerz. Solange man schreibt, ist der Untergang gebannt, findet Vergänglichkeit nicht statt, und darum schreibe ich: um die Welt, die pausenlos in Nichts zerfällt, zu ertragen. (S.205) 
ZUSAMMENFASSUNG

In dieser Arbeit wurde versucht, Günter Kunerts künstlerische Entwicklung, die sich über fast drei Jahrzehnte erstreckt, zu verfolgen. Da sich diese Entwicklung unter den Gegebenheiten eines diktatorischen Staates ereignete, mußte sie auch aus politischer Sicht betrachtet werden. Der junge Schriftsteller, zu Beginn der fünfziger Jahre noch zutiefst vọ einer historischen Vergangenheit beeindruckt, reflektiert ihre Schrecken in Warngedichten. Indem er die Erinnerung an die Katastrophen der jüngsten Vergangenheit wachruft, hofft er, das moralische Bewußtsein des Lesers so zu beeinflussen, daß er eine zukünftige Wiederholung menschlicher Grausamkeiten nie zuließe. Diese Gedichte bilden die Basis zu seiner Suche nach dem neuen Menschen, den er in seinem neuen Staat zu finden hofft. Kunerts adressierende, wegweisende Gedichte bezwecken, dem neuen Menschen Anleitung und Richtlinien bei der Veränderung der Welt zu geben. Brechts Einfluß ist in diesen lehrgedichten offensichtlich. Die Werke der fünfziger Jahre reflektieren einen tatkräftigen Optimismus. Die neue Welt sein im Aufbau begriffener Staat - scheint ihm Realität zu werden. Er ist bestrebt, den lebendigen Entwicklungsprozeß ästhetisch zu gestalten und künstlerisch aktiv an ihm beteiligt zu sein. Da für Kunert das Grundmotiv immer die gegenwärtige Wirklichkeit ist, reflektieren seine frühen Werke auch seinen optimistischen Zeitgeist. Den Glauben an einen gemeinsamen Weg, an Solidarität, drückt er in sozialistischer Didaktik aus. Von Seiten der Partei bringt inm das Lob und Anerkennung ein. Diese Phase ist jedoch kurzlebig, da Kunert sich bald künstlerisch eingeschränkt fühlt. Die parteilich diktierten Richtlinien zur Förderung des soziali- 
stischen Realismus in der Literatur zwingen ihn in einen Stoffkreis, dem er bereits kïnstlerisch entwachsen ist. In den späten fünfziger Jahren, und besonders nach den Ereignissen des Jahres 1961, sind in seinen Schriften Spuren von Enttäuschung und wachsender Skepsis dem politischen System gegenüber zu bemerken. Diese Wandlung bringt ihm jedoch Tadel und Kritik der Partei ein. Obwohl er überzeugter Sozialist bleibt und gesellschaftIiche Veränderungen erhofft, wendet sich seine Dialektik jedoch immer mehr der Skepsis, Ironie und Kritik zu. Das sardonische Gedicht, "Wie ich ein Fisch wurde", kann als Wendepunkt in Kunerts künstlerischer und ideologischer Entwicklung angesehen werden. Die Werke der sechziger Jahre zeigen mehr und mehr seine Loslösung von dem Gefühl der Solidarität: er wendet sich vom "Wir" zum "Ich". Mitte der sechziger Jahre wird auch Kafkas Einfluß bemerkbar, wie beispielsweise in den Prosasammlungen Tagträu-

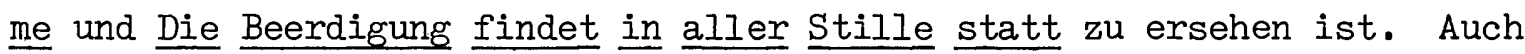
seine Aphorismen, "In den Herzkammerm der Echos" und "Unterschiede", zeigen kafkaeske Zïge auf. Von dem im ersten Kapitel besprochenen Einfluß Brechts scheint Kunert sich fast ganz abgewandt zu haben. Das Grundgefühl vieler seiner Schriften der späten sechziger Jahre ist von Hoffnungslosigkeit, Melancholie und annähernder Resignation geprägt. Staatliche Kritik erfolgt wiederholt und weist im Besonderen auf nihilistische Merkmale in Kunerts Werken hin. Auch die ständig zunehmende Subjektivierung seiner Schriften ịst Anlaß zu Kritik. In den Augen des Staates unterminieren diese Elemente die sozialistische Gesellschaft. Das sozialistische Menschenbild kann die Isoliertheit eines Individuums nicht akzeptieren. Alexander Abusch stellt "Die Frage an den Dichter Günter Kunert":

Hat er denn all das vergessen, was seine großen Lehrer Becher und Brecht ihn einstmals gelehrt? Wie anders kann es in einer 
Reihe seiner neueren Gedichte zu einer Rückentwicklung vom Wir zum Ich kommen, in einer Zeit, in der unsere Entwicklung bei mehr und mehr Menschen vom Ich zum Wir geht? 1

Der Mensch im Sozialismus ist also nicht von Einsamkeit, Vereinzelung und Entfremdung bedroht; eine unrealistische Verschönerung, die der Wirklichkeitsebene nicht entspricht. Da die gegenwärtige Wirklichkeit - immer Grundmotiv bei Kunert - ihn aber mit dieser menschlichen Problemạtịk konfrontiert, so ist sie auch in seinen Werken der siebziger Jahre reflektiert. Als Randbemerkung sei hier angeführt, daß Kunert alle Bücher seiner Frau widmet. Die Widmungen bestehen ausschließlich aus Variationen von "Fïr Marianne - Zueignung aus Zuneigung". Nur die Widmung in Unterwegs nach Utopia (1978), seinem neusten Gedichtband, weist auf mehr als Zuneigung hin. Diese Zueignung kann als ein Bekenntnis zu der menschlichen Problematik gesehen werden, die im sozialistischen Menschenbild nicht enthalten sein soll:

\section{Marianne}

der Teilhaberin und Therapeutin meiner Kümmernisse und Ängste zugeeignet

Seine Kümmernisse und Ängste scheinen in den letzten zwei Jahren zugenommen zu haben. Das bezeugt die Mehrzahl der Gedichte in Unterwegs nach Utopia. Kunerts gegenwärtige Problematik liegt hauptsächlich in dem politischen Geschehen, das bereits viele seiner Kollegen betroffen hat. Er war einer der ersten Unterzeichner des öffentlichen Protestschreibens im Falle Biermann. Biermanns erzwungenes Exil signalisiert den Anfang in einer Reihe solcher Fälle und es ist anzunehmen, daß Kunert ein ähnliches Schicksal befürchtet. Die Entscheidung, in der DDR zu beliben, hatte er vor langer Zeit getroffen und auch heute noch zieht er den östlichen Teil 
Deutschlands vor. Da aber Schreiben lebensnotwendig für ihn ist - wie er selbst sagt - muß er eine weitere Entscheidung treffen. Er hat die Wahl, weiterhin so zu schreiben, wie er die Wirklichkeit erfaßt und beurteilt und damit geht er ein Risiko ein, selbst Opfer eines aufgezwungenen Exils zu werden. Andere Möglichkeiten wären, nur staatlich erwünschte Literatur zu "produzieren" oder sich in die innere Emigration zurückzuziehen. Wenn man jedoch Günter Kunerts Gesamtwerk der letzten drei Jahrzehnte überblickt, so ist es offensichtlich, daß die beiden letzteren Möglichkeiten für diesen Schriftsteller nicht annehmbar sind. In einem Interview mit der International Herald Tribune stellt er sich zwei Fragen, die er selbst beantwortet: "Die wichtigste Frage für mich ist: Habe ich die Möglichkeit zu schreiben? Bis jetzt kann ich diese Frage bejahen. Dann muß ich mich fragen, ob das, was ich schreibe, auch verlegt werden kann, und diesbezüglich habe ich Hoffnung."2

In den letzten anderthalb Jahren ist es jedoch unmöglich gewesen, Kunerts Bücher in der DDR zu kaufen. Durch seinen Verlag in der Bundesrepublik ist er jedoch verlegt worden. Es ist anzunehmen, daß diese Ausgaben auf irgendeine Weise ihren Weg wieder zurück in die DDR gefunden haben. Und somit ist - wenn auch auf Umwegen - die Verbindung zwischen einem Schriftsteller und seinen Lesern wiederhergestellt. Und es ist gerade diese Verbindung, die Kunert als Grund dafür angibt, in der DDR bleiben zu wollen. In dem gleichen Zeitungsinterview drückt er diese Gedanken aus:

Vielleicht klingt es überheblich, aber mein Entschluß zu bleiben, hängt mehr von meinen Lesern ab. Es gibt viele unter ihnen, die das brauchen, was ich schreibe. Die Situation eines Schriftstellers in einem sozialistischen Land ist eine andere ... Sie müssen die Dinge umschreiben ... Und hier liegt der Grund dafür, warum ich mich als ein Teil dieser Gesellschaft sehe: ich werde gebraucht. 3 
FUBNOTEN

Einleitung

${ }^{1}$ John Flores, Poetry in East Germany: Adjustments, Visions, and Provocations 1945-1970 (New Haven and London: Yale University Press, 1971), S. 12.

\author{
${ }^{2}$ Ebd., S. 12 . \\ 3 Ebd., S. 12 .
}

Kapitel I: Der Frühe Einfluß Brechts

${ }^{1}$ Persönliches Gespräch mit dem Autor im September 1975.

2 Günter Kunert, Erinnerungen an einen Planeten (München: Carl Hanser Verlag, 1965), S. 7 .

3 Gregor Laschen, Lyrik in der DDR: Anmerkungen zur Sprachverfassung des modernen Gedichts (Frankfurt: Athenäum Verlag, Bd. 4, 1971), S. 96.

4 Ebd., S. 96.

5 Giinter Kunert, Verkündigung des Wetters (München: Carl Hanser Verlag, 1966), S. 21.

6 Kunert, Erinnerungen an einen Planeten, s. 43.

7Ebd., S. 41. (Kapitel III bespricht dieses Gedicht näher.)

8 Bertolt Brecht, Schriften zur Literatur und Kunst II (Frankfurt: Suhrkamp Verlag, 1967), S. 11.

9 Günter Kunert, Warum schreiben: Notizen zur Literatur (Berlin und Weimar: Aufbau Verlag, 1976), S. 242.

${ }^{10}$ Brecht, Schriften zur Literatur und Kunst III, s. 17. 
${ }^{11}$ Brecht, Schriften zur Literatur und Kunst III, S. 37.

12 Bertolt Brecht, BB $\underline{\text { iber }}$ Lyrik (Frankfurt: Suhrkamp Verlag, 3. Auflage, 1968), S. 89 .

${ }^{13}$ Gïnter Kunert, Unter diesem Himmel (Berlin: Aufbau Verlag, 1955), S. 7 .

${ }^{14}$ Günter Kunert, Warnung vor Spiegeln (München: Carl Hanser Verlag, 1970), S. 87.

15 Ebd., S. 15 .

${ }^{16}$ Kunert, Erinnerungen an einen Planeten, S. 13.

$17_{\mathrm{Ebd}} .$, s. $63-65$.

${ }^{18}$ Bertolt Brecht, Gedichte II (Frankfurt: Suhrkamp Verlag, 1960), S. 126.

19Ebd., S. 128 .

20 Während der dreißiger Jahre ist in Brechts Lyrik und Prosa jedoch gelegentlich auch Anerkennung historischer Größe zu finden.

${ }^{21}$ Kunert, Warum schreiben, S. 137 .

$22 \mathrm{Ebd} ., \mathrm{S} .138$.

23 Kunert, Warnung vor Spiegeln, s. 37 .

${ }^{24}$ Günter Kunert, Tagträume in Berlin und andernorts (München: Carl Hanser Verlag, 1972), S. 91.

25 Kunert, Erinnerungen an einen Planeten, s. 28.

Kapitel II: Die Wendung zu Kafka

${ }^{1}$ Joachim Walther, Meinetwegen Schmetterlinge: Gespräche mit Schriftstellerm (Berlin: Buchverlag Der Morgen, 1973), s. 90 .

2 Kunert, Verkïndigung des Wetters, s. 38. 
3 Kunert, Erinnerungen an einen Planeten, S. 59.

${ }^{4}$ Kunert, Verkïnigung des Wetters, S. 83.

5 Günter Kunert, Die Schreie der Fledermäuse: Geschichten, Gedichte, Aufsätze (Gütersloh: Bertelsmann Reinhard Mohn OHG, 1978), S. 258 :

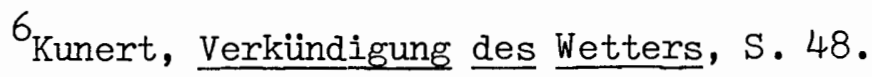

7 Hans-Günther Thalheim, et al., Hrsg., Geschichte der Literatur der Deutschen Demokratischen Republik (Berlin: Volk und Wissen Volkseigener Verlag, 1976), S. 728 .

8 Klaus Werner, "Günter Kunert" in Literatur der DDR in Einzeldarstellungen (Stuttgart: Alfred Kröner Verlag, 1972), S. 536.

9 Kunert, Warnung vor Spiegeln, S. 20.

${ }^{10}$ Kunert, Erinnerungen an einen Planeten, S. 54 .

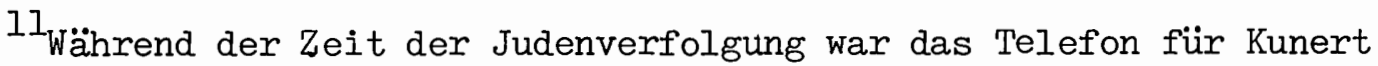
Drohung und Warnung zugleich. In seinem Essay, "Ohne Bilanz", das in Tagträume in Berlin und andernorts enthalten ist, macht er diesbezüglich eine Bemerkung.

12 Kunert, Tagträume in Berlin und andernorts, s. 27.

13 Ebd., S. 27 .

14 Ebd., S. 27 .

15 Jürg Beat Honegger, Das Phänomen der Angst bei Kafka (Berlin: Erich Schmidt Verlag, 1975), S. 58.

16 Kunert, Tagträume, s. 27.

17 Kunert, Die Schreie der Fledermäuse, S. 281.

18 Kunert, Tagträume, s. 87.

19 Günter Kunert, Unterwegs nach Utopia: Gedichte (München: Garl Hanser Verlag, 3. unveränderte Auflage, 1978), s. 80.

20 "Neues vom Amt II" fehlt in dieser Ausgabe oder existiert nicht. 
$21_{\text {Kunert, Unterwegs nach Utopia, }}$ S. 81.

22 Dieses Gedicht erscheint nur in dem Lyrikband Verkünigung des Wetters. In allen anderen Ausgaben, die für diese Arbeit gebraucht wurden, fehlt "Interfragmentarium".

23 Kunert, Verkündigung des Wetters, s. 80-81.

${ }^{24}$ Alexander Abusch, "Die Frage an den Dichter Günter Kunert" in Literatur im Zeitalter des Sozialismus (Berlin und Weimar: Aufbau Verlag, 1967), S.713.

$25_{\text {Ebd., s. }} 713$.
$26_{\text {Ebd., s. }} 714$.
$27_{\text {Ebd., s. } 714 .}$

Kapitel III: Naturbild als Parabel

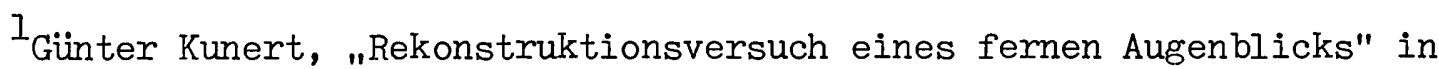
Eröffnungen: Schriftsteller über ihr Erstlingswerk, Hrsg. Gerhard Schneider (Berlin und Weimar: Aufbau Verlag, 1974), s. 160.

$2_{\text {Kunert, Erinnerungen an einen Planeten, }}$ s. 38.

3 Persönliches Gespräch mit dem Autor im September 1975.

${ }^{4}$ C. Valerii Catulli, Carmina (Oxford: Oxford University Press, 1958), S. $3-4$.

5unert, Erinnerungen an einen Planeten, S. 29.

$6_{\mathrm{Ebd} ., \mathrm{S} .} 41$.

7 Günter Kunert, Der Mittelpunkt der Erde (Berlin: Eulenspiegel Verlag, 1975), S. 60. (Die folgenden $Z i$ tațe beziehen sich auf diese Ausgabe.)

$8_{\mathrm{Ebd} ., \text { S. } 60 .}$

9 Thalheim, Geschichte der Literatur der Deutschen Demokratischen Republik, S. 495. 
${ }^{10}$ Ebd., S. 728 .

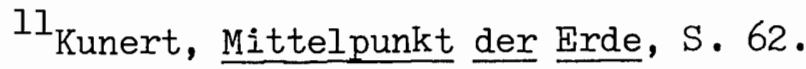

$12 \mathrm{Ebd} ., \mathrm{S} .63$.

${ }^{13}$ Flores, Poetry in East Germany, S. 292.

14 Werner Brettschneider, Zwischen literarischer Autonomie und Staatsdienst: Die Literatur der DDR, zit. nach Peter Hamm, (Berlin: Erich Schmidt Verlag, 2. Auflage, 1974), S. 225-226.

\section{Kapitel IV: Stadtbeschreibungen}

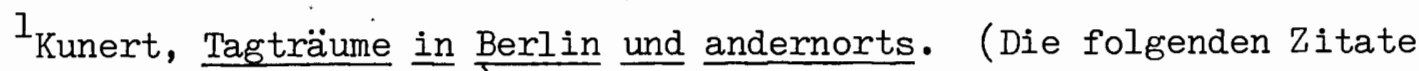
sind diesem Band entnommen.)

2 Günter Kunert, Ortsangaben (Berlin und Weimar: Aufbau Verlag, 1974), S. 101. (Die weiteren Zitate sind diesem Band entnommen.)

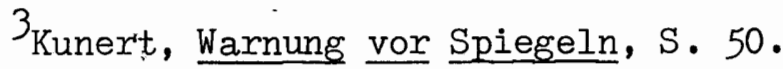

${ }^{4}$ Kunert, Erinnerungen an einen Planeten, S. 17.

$5 \mathrm{Ebd} ., \mathrm{S} \cdot 35$.

Kapitel V: Paradoxie als Prinzip

${ }^{1}$ Kunert, Warum schreiben, S. 275. (Die weiteren Zitate sind diesem Band entnommen.)

2 Kunert, Tagträume, s. 83.

3Ebd., S. 83.

4 Ebd., S. 44 .

${ }^{5}$ Kunert, Warum schreiben, S. 228.

$6_{\mathrm{Ebd} .,}, \mathrm{S} .228$. 
Kapitel VI: Das. Lyrische Ich

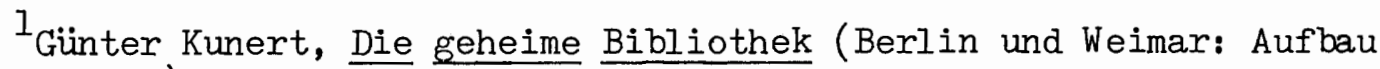
Verlag, 1973), S. 279.

2Ebd., S. 280.

3Ebd., S. 280.

4 Kunert, Erinnerungen an einen Planeten, S. 70.

5 Kunert, Die Schreie der Fledermäuse, s. 376.

6 Kunert, Erinnerungen, s. 79.

7 Günter Kunert, Offener Ausgang: Gedichte (Berlin und Weimar: Aufbau Verlag, 1975), S. 104.

8 Günter. Kunert, Im weiteren Fortgang (München: Carl Hanser Verlag, $1974)$, S. 109.

9unert, Warum schreiben, S. 293.

Kapitel VII: Das "Bewußtsein" des Gedichts

${ }^{1}$ Kunert, Warum schreiben. (Die weiteren Zitate sind diesem Band entnommen.)

2 Kunert, Offener Ausgang, S. 111 .

3Ebd., S. 112 .

4 Kunert, Warum schreiben, S. 202.

5 Ebd., S. 205.

${ }^{6}$ Kunert, Warnung vor Spiegeln, S. 28.

${ }^{7}$ Kunert, Warum schreiben, S. 205.

8 Kunert, Im weiteren Fortgang, s. 30. 


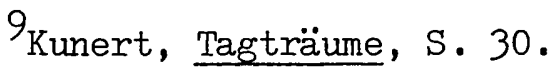

10 Kunert, Unterwegs nach Utopia, S. 293.

${ }^{11_{\text {Kunert, Warum }}}$ schreiben, S. 261. (Die weiteren Zitate entstammen dieser Ausgabe.)

$\triangle$ USAMMENFASSUNG

${ }^{1}$ Alexander Abusch, "Die Frage an den Dichter Günter Kunert" in Literatur im Zeitalter des Sozialismus (Berlin und Weimar: Aufbau Verlag, 1967), S. 773.

${ }^{2}$ Michael Getler, "Writing around the Edges in East Germany" in International Herald Tribune, Paris, 13. März 1978.

$3_{\mathrm{Ebd}}$. 


\section{LITERATURVERZEICHNIS}

Abusch, Alexander. Literatur im Zeitalter des Sozialismus. Berlin und Weimar: Aufbau Verlag, 1967.

Auf einer Straße: zehn Geschichten. Berlin und Weimar: Aufbau Verlag, 1968.

Brecht, Bertolt. BB über Lyrik. Frankfurt: Suhrkamp Verlag, 3. Auflage, 1968.

- Gedichte II, III, IX, X. . Frankfurt: Suhrkamp Verlag, $1960,1961,1965$ und 1967.

- Schriften zur Literatur und Kunst II, III. Frankfurt: Suhrkamp Verlag, 1967.

Brettschneider, Werner. Zwischen literarischer Autonomie und Staatsdienst: Die Literatur der DDR. Berlin: Erich Schmidt Verlag, 2. Auflage, 1974 .

Catulli, C. Valerii. Carmina. Oxford: Oxford University Press, 1958.

Catullus, C. Valerius. Odi et Amo: The complete poetry of Catullus. Transl. by Roy Arthur Swanson. Indianapolis and New York: The Liberal Arts Press, Inc., 1959.

- The Poems of Catullus. Transl. by Horace Gregory. New York: Covici-Friede Publishers, 1931.

- The Poems of Catullus. Transl. by Peter Whigham. Harmondsworth, Middlesex, England: Penguin Books Ltd., 1966.

Diersch, Manfred, und Hartinger, Walfried, Hrsg. Literatur und Geschichtsbewußtsein: Entwicklungstendenzen der DDR-Literatur in den sechziger und siebziger Jahren. Berlin und Weimar: Aufbau Verlag, 1976.

Flores, John. Poetry in East Germany: Adjustments, Visions, and Provocations 1945-1970. New Haven and London: Yale University Press, 1971.

Franke, Konrad. Erzähler aus der DDR. Tübingen und Basel: H. Erdmann Verlag, 1973.

- Hrsg. Kindlers Literaturgeschichte der Gegenwart: Literatur der DDR. Zürich und München: Kindler Verlag, 1974.

Getler, Michael. "Writing around the Edges in East Germany." In International Herald Tribune. Paris: 13. März 1978. 
Gumpel, Lieselotte. "Concrete" Foetry from East and West Germany: The Language of Exemplarism and Experimentalism. New Haven and London: Yale University Press, 1976.

Hofacker, Erich. "Günter Kunert and the East German image of man." In Monatshefte für deutschen Unterricht, deutsche Sprache und Iiteratur, $66,1974,36 \overline{6-3} 80$.

Honegger, Jürg Beat. Das Phänomen der Angst bei Franz Kafka. Berlin: Erich Schmidt Verlag, 1975.

Johannes-R.-Becher-Archiv, Deutsche Akademie der Künste, Hrsg. Erinne-

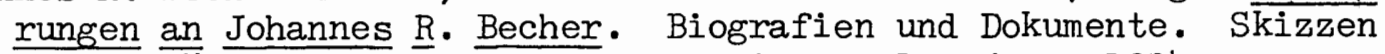
und Aufsätze. Leipzig: Verlag Philipp Reclam jun., 1974.

Korall, Harald, und Liersch, Werner, Hrsg. Erfahrungen: Erzähler der DDR: Anthologie. Halle(Saale): Mitteldeutscher Verlag, 1969.

Kritik 75: Rezensionen zur DDR-Literatur. Halle(Saale): Mitteldeutscher Verlag, 1975 .

Kunert, Günter. "Das Bewußtsein des Gedichts." Akzente. Zeitschrift fïr Literatur, Heft 2, 1970, 101.

- Der andere Planet: Ansichten von Amerika. Berlin und Weimar: Aufbaù Verlag, 1974.

- Der Mittelpunkt der Erde. Berlin: Eulenspiegel Verlag, 1975.

- Der ungebetene Gast. München: Carl Hanser Verlag, 1965.

- Die Beerdigung findet in allex Stille statt: Erzählungen. Mïnchen: Carl Hanser Verlag, 1968.

- Die geheime Bibliothek. Berlin und Weimar: Aufbau Verlag 1973.

- Die Schreie der Fledermäuse: Geschichten, Gedichte, Aufsätze. Gütersloh: Bertelsmann Reinhard Mohn OHG, 1978. Verlag, 1965.

- Erinnerungen an einen Planeten. München: Carl Hanser

- Im Namen der Hüte: Roman. München: Carl Hanser Verlag,

1967 .

- Im weiteren Fortgang. München: Carl Hanser Verlag, 1974.

- "Legende vom Schal." Auf einer Straße: zehn Geschichten. Berlin und Weimar: Aufbau Verlag, $1968,61-77$.

- Offener Ausgang: Gedichte. Berlin und Weimar: Aufbau 
Kunert, Günter. Ortsangaben. Berlin und Weimar: Aufbau Verlag, 1974.

- "Rekonstruktionsversuch eines femen Augenblicks." In Eröffnungen: Schriftsteller über ihr Erstlingswerk. Berlin und Weimar: Aufbau Verlag, 1974, 160-163.

- Tagträume in Berlin und andernorts. München: Carl Hanser Verlag, 1972.

- Unter diesem Himmel. Berlin: Aufbau Verlag, 1955.

- Unterwegs nach Utopia: Gedichte. München: Carl Hanser Verlag, 3. unveränderte Auflage, 1978.

- Verkïndigung des Wetters. München: Carl Hanser Verlag,

1966.

- Warnung vor Spiegeln. München: Carl Hanser Verlag, 1970.

- Warum schreiben: Notizen zur Literatur. Berlin und Weimar: Aufbau Verlag, 1976.

Laschen, Gregor. Lyrik in der DDR: Anmerkungen zur Sprachverfassung des modernen Gedichts, Bd. 4, Frankfurt: Athenäum Verlag, 1971.

Löffler, Anneliese, Hrsg. Auskünfte: Werkstattgespräche mit DDR-Autoren. Berlin und Weimar: Aufbau Verlag, 1976.

Miiller, Klaus-Detlef. Die Funktion der Geschichte im Werk Bertolt Brechts: Studien zum Verhältnis von Marxismus und Ästhetik. Tibingen: Max Niemeyer Verlag, 1967.

Politzer, Heinz. Franz Kafka: Parable and Paradox. Ithaca, N.Y.: Cornell University Press, 1962.

Raddatz, Fritz J. Traditionen und Tendenzen - Materialien zur Literatur der DDR. Frankfurt: Suhrkamp Verlag, 1972.

Reich-Ranicki, Marcel. Deutsche Literatur in West und Ost: Prosa seit 1945. München: R. Piper Verlag, 1966.

- Literarisches Leben in Deutschland: Kommentare und Pamphlete. München: R. Piper Verlag, 1965. - Zur Literatur der DDR. München: R. Piper Verlag, 1974 .

Rumold, Rainer. "'Warnung vor Spiegeln': Zur kulturpolitischen und sprachlichen Problematik des 'schwarzen' Lehrgedichts Günter Kunerts." In Monatshefte, 68, Nr. 4, 1976, 425-35.

Sander, Hans-Dietrich. Geschichte der schönen Literatur in der DDR: Ein Grundriß. Freiburg: Verlag Rombach, 1972. 
Schneider, Gerhard, Hrsg. Erörfnungen: Schriftsteller über ihr Erstlingswerk. Berlin und Weimar: Aufbau Verlag; 1974.

Schöne, Albrecht. Uber politische Lyrik im 20. Jahrhundert. Göttingen: Vandenhoek und Ruprecht, 3. Auflage, 1972.

Thalheim, Hans-Günther, et al., Hrsg. Geschichte der Literatur der Deutschen Demokratischen Republik. Berlin: Volk und Wissen Volkseigener verlag, 1976.

roigtländer, Annie, Hrsg. Liebes- und andere Erklärungen: Schriftsteller über Schriftsteller. Berlin und Weimar: Aufbau Verlag, 1974.

Wagenbach, Klaus. Franz Kafka: Eine Biografie seiner Jugend: 1883-1912. Berlin: Francke Verlag, 1958.

Walther, Joachim. Meinetwegen Schmetterlinge: Gespräche mit Schriftstellern. Berlin: Buchverlag der Morgen, 1973.

Walwei-Wiegelmann, Hedwig. "Zur Lyrik und Prosa Giinter Kunerts." In Deutschunterricht, $\mathrm{Nr}$. 5, Oktober 1969, $134-44$.

Was zählt ist die Wahrheit: Briefe von Schriftstellern der DDR. Halle (Saale): Mitteldeutscher Verlag, 1975.

Weinberg, Kurt. Kafkas Dichtungen: Travestien des Mythos. München: Francke Verlag, 1963.

Werner, Klaus. "Gïnter Kunert." In Literatur der DDR in Einzeldarstellungen. Stuttgart: Alfred Kröner Verlag, $\overline{1972}, 523-47$.

- "Zur Brecht-Rezeption bei Günter Kunert und H.M. Enzensberger." Weimarer Beiträge, Brecht Sonderheft 1-2, 1968, 61-70.

Zeißler, Armin. "Notizen über Günter Kunert." Sinn und Form, Nr. 3, 1970, 787-93. 